\title{
Value of sharing cow reference population between countries on reliability of genomic prediction for milk yield traits
}

\author{
M. Haile-Mariam, ${ }^{1 *}$ I. M. MacLeod, ${ }^{1}$ S. Bolormaa, ${ }^{1}$ C. Schrooten, ${ }^{2}$ E. O'Connor, ${ }^{3}$ G. de Jong, ${ }^{2}$ H. D. Daetwyler, ${ }^{1,4}$ \\ and J. E. Pryce ${ }^{1,4}$ \\ ${ }^{1}$ Agriculture Victoria, Department of Jobs, Precincts and Regions, Bundoora, VIC 3083, Australia \\ ${ }^{2} \mathrm{CRV}, 6800 \mathrm{AL}$ Arnhem, the Netherlands \\ ${ }^{3}$ CRV Ambreed, Hamilton, 3216 New Zealand \\ ${ }^{4}$ School of Applied Systems Biology, La Trobe University, Bundoora, VIC 3083, Australia
}

\section{ABSTRACT}

Increasing the reliability of genomic prediction (GP) of economic traits in the pasture-based dairy production systems of New Zealand (NZ) and Australia (AU) is important to both countries. This study assessed if sharing cow phenotype and genotype data of NZ and AU improves the reliability of GP for NZ bulls. Data from approximately 32,000 NZ genotyped cows and their contemporaries were included in the May 2018 routine genetic evaluation of the Australian Dairy cattle in an attempt to provide consistent phenotypes for both countries. After the genetic evaluation, deregressed proofs of cows were calculated for milk yield traits. The April 2018 multiple across-country evaluation of Interbull was also used to calculate deregressed proofs for bulls on the NZ scale. Approximately 1,178 Jersey (Jer) and 6,422 Holstein (Hol) bulls had genotype and phenotype data. In addition to NZ cows, phenotype data of close to 60,000 genotyped Australian (AU) cows from the same genetic evaluation run as NZ cows were used. All AU and NZ females were genotyped using low-density SNP chips $(<10 \mathrm{~K}$ SNP) and were imputed first to $50 \mathrm{~K}$ and then to $\sim 600 \mathrm{~K}$ (referred to as high density; HD). We used up to 98,000 animals in the reference populations, both by expanding the NZ reference set (cow, bull, single breed to multi-breed set) and by adding AU cows. Reliabilities of GP were calculated for 508 Jer and 1,251 Hol bulls whose sires are not included in the reference set (RS) to ensure that real differences are not masked by close relationships. The GP was tested using 50K or high-density SNP chip using genomic BLUP in bivariate (considering country as a trait) or single trait models. The RS that gave the

Received June 26, 2019.

Accepted October 24, 2019.

*Corresponding author: Mekonnen.HaileMariam@agriculture.vic .gov.au highest reliability for each breed were also tested using a hybrid GP method that combines expectation maximization with Bayes R. The addition of the AU cows to an NZ RS that included either NZ cows only, or cows and bulls, improved the reliability of GP for both NZ Hol and Jer validation bulls for all traits. Using single breed reference populations also increased reliability when NZ crossbred cows were added to reference populations that included only purebred NZ bulls and cows and AU cows. The full multi-breed RS (all NZ cows and bulls and AU cows) provided similar reliabilities in NZ Hol bulls, when compared with the single breed reference with crossbred NZ cows. For Jer validation bulls, the RS that included Jer cows and bulls and crossbred cows from NZ and Jer cows from AU was marginally better than the all-breed, all-country RS. In terms of reliability, the advantage of the HD SNP chip was small but captured more of the genomic variance than the $50 \mathrm{~K}$, particularly for Hol. The expectation maximization Bayes R GP method was slightly (up to 3 percentage points) better than genomic BLUP. We conclude that GP of milk production traits in NZ bulls improves by up to 7 percentage points in reliability by expanding the NZ reference population to include AU cows.

Key words: genomic prediction, genotyped cows, sharing reference cows, multi-breed prediction

\section{INTRODUCTION}

Genetic progress using genomic selection largely depends on the reliability of the genomic breeding value (BV), which in turn depends on the size of the reference population, the heritability of the trait and the linkage disequilibrium between markers and quantitative trait loci (e.g., Daetwyler et al., 2008; Goddard, 2009). Of all the factors that influence the reliability of genomic prediction (GP), the potential to increase reliability is greatest through expanding the reference population. Thus, many countries have increased the size of their 
reference populations by genotyping bulls with large numbers of progeny (Hayes et al., 2009; VanRaden et al., 2009; Su et al., 2010). In addition, several countries have improved the reliability of GP by exchanging genotype data of bulls between countries, and by using deregressed proofs of multiple across-country evaluation (MACE) from Interbull (Lund et al., 2011; VanRaden et al., 2012). Increasing the reference population size by genotyping cows has also increased the reliability of genomic BV in several countries (Wiggans et al., 2011; Dassonneville et al., 2012; Pryce et al., 2017), despite the possibility of introducing bias. In contrast to bulls, only a few studies have assessed whether sharing cow phenotype and genotype data among countries can improve the reliability of genomic BV for either numerically small dairy cattle populations (e.g., Jenko et al., 2017), or for novel and expensive to measure traits (e.g., de Haas et al., 2012; Pryce et al., 2012).

A joint project by DairyBio (an initiative of Agriculture Victoria Research and Dairy Australia, Melbourne, Australia) and CRV New Zealand (a subsidiary of CRV Netherland, Arnhem, the Netherlands) was established with the aim of increasing the reliability of GP in the pasture-based dairy production systems of New Zealand (NZ) and Australia (AU). One of the aims of the project is to assess whether sharing cow data helps to improve the reliability of GP and explore the best approach to using this information. The success of sharing reference populations between countries could depend on the similarities of genotypes from each country (Habier et al., 2010) and their production systems (e.g., VanRaden et al., 2012). There is considerable similarity between AU and NZ in the dairy production system (predominantly pasture-based systems) as well as the genotypes used.

When considering the use of phenotype and genotype data from different countries for GP, it is possible to consider performance in different countries to be the same trait (i.e., ignoring possible genotype by environment interaction, $\mathbf{G} \times \mathbf{E}$ ), or as 2 separate correlated traits (accounting for $\mathrm{G} \times \mathrm{E}$ interaction). One way to test the best approach is to assess the relative advantages in terms of reliability and bias in an independent set of validation bulls, that have accurate phenotypes largely from their country of origin. Additionally, by using cow phenotype data recorded in the 2 countries and linking them through their genotype data, instead of through bulls that have daughters in the 2 countries, we can re-estimate genetic correlations between the 2 countries for different traits and compare them with corresponding genetic correlations used by Interbull for MACE. We can also estimate the variance explained by genomic data for different traits in the 2 countries and assess the quality of the response variables used for analyses in the 2 countries for both Holstein $(\mathbf{H o l})$ and Jersey (Jer) breeds.

We initially concentrated on GP using data of Jer and Hol breeds separately, then assessed different scenarios by including various crossbred cows, and finally we assessed the benefit of an all-breed GP by validating using Jer and Hol bulls with reliable MACE proofs. The inclusion of crossbred animals in the reference set (RS) is appealing for genomic evaluation for both NZ and AU because on many dairy farms crossing between breeds has been practiced for several generations (de Roos et al., 2008; Pryce et al., 2011). When using mixed breeds and data from different countries even within the same breed, using a high-density (HD) SNP chip may also help to increase the reliability, because these SNP are likely to be closer to the QTL and share the same linkage disequilibrium phase between marker (SNP) and QTL (de Roos et al., 2009; Erbe et al., 2012). However, currently in most countries the $50 \mathrm{~K}$ SNP chip is used for routine genomic evaluations and therefore it is useful to compare the difference in reliability of prediction between HD and 50K SNP chip.

In this study the primary objective is to assess whether the reliability of GP for NZ Hol and Jer validation bulls can be improved by adding cow genotype and phenotype data from AU to the NZ bull and cow RS using either single or bi-variate models. We also assessed the benefits of adding AU cows after including all the available cow and bull populations that could be used as the RS in NZ. For most scenarios in this study genomic best linear unbiased prediction (GBLUP) was used for prediction because of its flexibility (e.g., univariate and bivariate analyses) and the computational ease when a large number of animals (up to 98,000) are included in the RS. However, when HD SNP and data of different breeds are in the RS, GP methods that assume nonnormal prior distributions of SNP effects, such as Bayes $\mathrm{R}$ have been reported to outperform GBLUP (e.g., Erbe et al., 2012). Therefore, the reliability and bias of GP from GBLUP were compared with the hybrid variant of the Bayes R method (EM-Bayes R) developed by Wang et al. (2016) that implements an expectation maximization module followed by a reduced number of Markov chain Monte Carlo iterations.

\section{MATERIALS AND METHODS}

\section{Phenotype Data}

Cow Phenotype Data. Test day milk production and pedigree data were obtained from the DairyNZ (Hamilton, New Zealand) core trait database. The 
Table 1. Number of animals with mean and SD for milk, fat, and protein yield deregressed proofs of cows from Australia (AU) and New Zealand (NZ), (in parentheses) bulls used as reference from NZ, and a validation set from NZ

\begin{tabular}{|c|c|c|c|c|}
\hline Group $^{1}$ & $\mathrm{n}$ & Milk & Fat & Protein \\
\hline NZ Hol cows & 10,944 & $862(492)$ & $35.4(20.0)$ & $33.1(12.2)$ \\
\hline AU Hol cows & 50.583 & $1.389(640)$ & $41.7(23.7)$ & $42.4(15.3)$ \\
\hline $\mathrm{NZ} \mathrm{Hol} \mathrm{bulls}^{2}$ & 4,380 & $621(441)$ & $2.3(17.1)$ & 12.8 (13.8) \\
\hline NZ Red Hol bulls ${ }^{2}$ & 791 & $570(529)$ & $6.8(22.2)$ & $13.1(17.3)$ \\
\hline NZ crossbred & 17,011 & $303(513)$ & $37.5(19.6)$ & $24.3(12.6)$ \\
\hline NZ Jer cows & 4,210 & $-336(381)$ & $35.1(18.0)$ & $12.3(10.8)$ \\
\hline AU Jer cows & 8,932 & $-24(543)$ & $31.8(22.9)$ & $16.6(14.3)$ \\
\hline NZ Jer bulls & 670 & $-757(258)$ & $-4.2(11.9)$ & $-14.7(7.7)$ \\
\hline \multicolumn{5}{|l|}{ Validation set } \\
\hline NZ Jer bulls & 508 & $-621(255)$ & $1.6(11.9)$ & $-8.3(8.2)$ \\
\hline NZ Hol bulls ${ }^{3}$ & 1,251 & $899(424)$ & $13.6(15.3)$ & $27.3(11.7)$ \\
\hline
\end{tabular}

${ }^{1} \mathrm{Hol}=$ Holstein; Jer $=$ Jersey.

${ }^{2}$ Of Hol, 67 and $25 \%$ were first tested in the Netherlands and NZ, respectively.

${ }^{3}$ Of the Hol bulls, 511 were first tested in NZ and the rest were mainly from the Netherlands.

data received from NZ consisted of close to 100,000 cows and almost 1.5 million test day records. The NZ cow data included data of genotyped cows and their contemporaries (ungenotyped cows that produced in the same herd-test day and year-season as genotyped cows). Finally, the data on NZ cows was merged with similar data from AU cows and were analyzed by DataGene (Melbourne, Australia) in May 2018. The EBV and deregressed breeding values (DRP) used for this study were calculated by applying genetic parameters and procedures used for routine genetic evaluations of AU dairy cattle (https://datagene.com.au/). The DataGene analyses produced DRP for milk production traits for about 32,000 NZ cows, which was jointly used with the DRP of close to $60,000 \mathrm{AU}$ cows that also had genotype data. The number of NZ and AU cows in each breed group is given in Table 1 .

Bull Phenotype Data. The NZ bull phenotypes were DRP calculated on the NZ scale using the April $2018 \mathrm{Hol}$ and Jer MACE (bull EBV) run by Interbull (https://interbull.org). The MACE proofs obtained from Interbull were deregressed using the full pedigree from Interbull for Hol and Jer separately. The deregression software developed by Liu (2009) produced DRP and effective daughter contributions for each bull with MACE proofs on the NZ scale. The procedure takes into account the genetic correlation matrix among Interbull member countries and uses a Gauss-Seidel algorithm to solve the equation system (Liu, 2009).

Table 1 shows the number of reference animals by sex, country, and breed with their mean DRP and standard deviation for milk yield (MY) traits. The number of Jer and Hol validation bulls with their mean DRP and standard deviation for MY traits is also shown in Table 1.

\section{Genotype Data}

In both countries, the cows that were selected for genotyping were from commercial herds that were known to perform better data recording (e.g., Pryce et al., 2017); in these herds most cows were genotyped, so preferential treatment that could introduce biased evaluations (i.e., EBV) is reduced. All NZ cows and most AU cows were genotyped with low-density SNP arrays including custom genotyping-by-sequencing (GBS) and selected SNP (XT) panels (approximately 8,800 SNP of which at least 6,900 overlap with the Illumina BovineSNP50 BeadChip, Illumina, San Diego, CA). The low-density genotypes were first imputed to the Illumina Bovine 50K SNP chip array and then to HD genotypes. The HD genotypes included 632,003 SNP from the Illumina BovineHD BeadChip in addition to 1,371 extra custom SNP genotyped on the GBS/XT panels. Some cows and most bulls were genotyped using the Illumina BovineSNP50 array (except 2,155 bulls with HD genotypes).

The HD or 50K SNP array genotypes were used for GP provided they passed quality control, which included removing SNP with minor allele frequency of below 0.002. The final HD genotype set included 633,374 SNP and the 50K genotypes included 40,850 SNP.

\section{Breed Distribution and Genotypes}

Accurate classification of the cows with genotype and phenotype data into the correct breed group is important in this study because we want to test the benefit of both single and multi-breed RS on the reliability of GP. The pedigree data used for genetic evaluation included a breed code for most cows (a 4-letter code based on 
the immediate parents such as FFJJ). However, some cows were classified into an "unknown" breed group. Also, in NZ, the use of crossbred bulls is common, and crossbreeding can occur across several generations. This means that the pedigree breed code may not accurately reflect genomic breed proportions. Therefore, principal component analyses (PCA) of a genomic relationship matrix (GRM) based on 8,490 low-density genotypes (with the majority being observed genotypes) for NZ and AU animals, including Hol and Jer purebred bulls, was used to classify cows into purebred Jer, pure bred Hol, or crossbred.

\section{Reference and Validation Set}

Holstein and Jersey bulls with DRP on the NZ scale were used as validation sets to assess if the reliability of genomic BV for NZ animals could be increased by adding AU cows to the NZ RS. Two sets of validation bulls that had reliable MACE proof were selected: one for Hol $(\mathrm{n}=1,251)$ and one for Jer $(\mathrm{n}=508)$. The Jer validation bulls were born after 2003 and were all first tested in NZ. The Hol validation bulls were born after 2005, and 53 and $45 \%$ were first tested in the Netherlands and NZ, respectively. Bulls whose sires were in the RS were not included in validation set. Additionally, any $\mathrm{NZ}$ or AU daughters of the validation bulls (i.e., cows) were not included in the RS. As a result, the data of 25 $\mathrm{AU}(2 \mathrm{Jer}+23 \mathrm{Hol})$ and $656 \mathrm{NZ}[289 \mathrm{Hol}(2.6 \%), 110$ Jer $(2.6 \%)$, and $257(1.5 \%)$ crossbred] cows that were progeny of validation bulls were excluded from the RS. This was done to ensure that very close relationships did not mask differences in accuracy between the range of reference populations and methods tested (e.g., Ma et al., 2019).
In Table 2 the range of reference populations used for this study is shown. Ten different sets or scenarios, starting from using NZ cows only (baseline) to using all animals (including AU cows) were compared. First, reliability of GP and bias for validation bulls based on NZ cows only (set 1) were compared with that based on NZ and AU purebred cows in a single trait (set 2 ), or bivariate model, where performances in NZ and AU were considered as 2 different traits (set 3 ). In the fourth option we combined NZ cows and bulls to provide the baseline accuracy, with only purebred NZ animals (set 4) and quantified the benefits of adding $\mathrm{AU}$ cows in univariate (set 5) or bivariate (set 6) models. Finally, still in the single breed context (Jer or Hol), we tested the value of adding in the crossbred NZ cows to the NZ cow and bull reference (set 7) and assessed if adding AU cows improves the prediction of the validation bulls. Then, we tested the value of multi-breed reference populations: combining $\mathrm{Hol}$ and Jer breeds in a single RS, including all NZ cows (crossbred, Hol, and Jer) with all Hol and Jer bulls (set 9) and then we added to this the AU Hol and Jer cows (set 10) to quantify the benefit of adding all AU cows.

\section{Statistical Analyses}

Most of the analyses in this study used GBLUP because of its flexibility and the time required for computation. However, the scenarios that gave the highest prediction reliability when using GBLUP were further compared with a GP method that accommodates a non-normal prior distribution of SNP effects, which also requires moderate computational resources (Wang et al., 2016). All the GBLUP analyses were implemented using MTG2 (Lee and van der Werf, 2016). The HD

Table 2. Reference populations (sets) from New Zealand (NZ) and Australia (AU) tested in single breed and multi-breed sets in either univariate or bivariate analyses

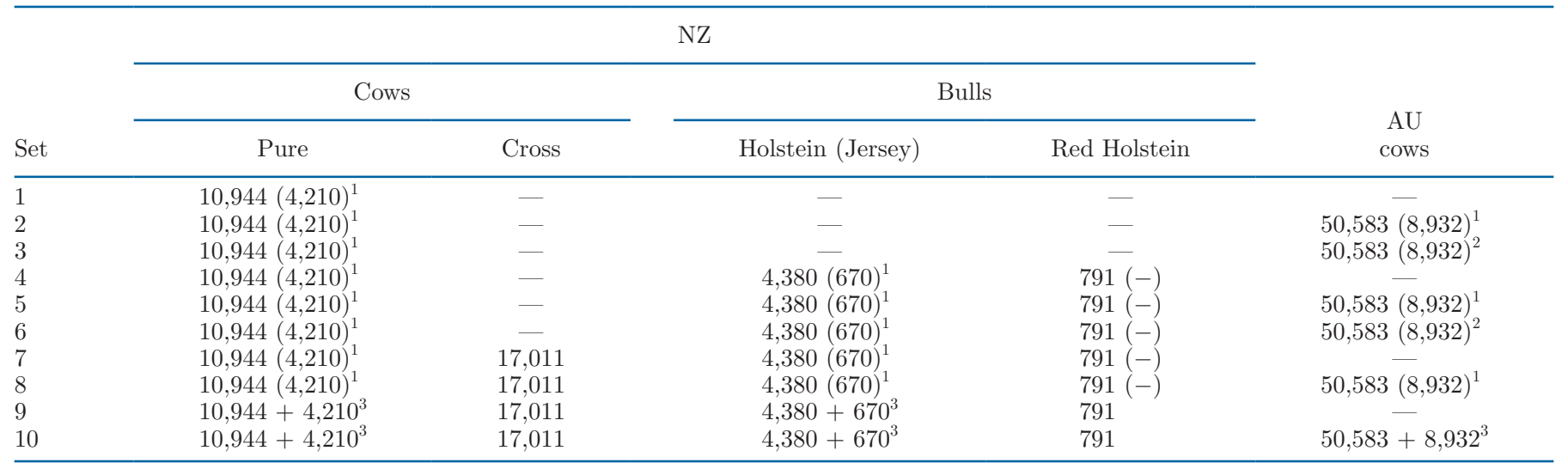

${ }^{1}$ Numbers (in parentheses) of NZ and AU Jersey cows or bulls used instead of Holstein are included in set 1 to 8.

${ }^{2}$ For example, milk yield in NZ and AU cows treated as 2 different traits.

${ }^{3}$ For set 9 and 10 the plus $(+)$ indicated joint reference sets where the 2 breeds were used. 
and 50K genotypes were used to create GRM following Yang et al. (2010). For each of the 2 breed groups (Hol and Jer) 2 GRM were formed. The first was based on purebred animals only (i.e., Jer or $\mathrm{Hol}$ ). The second GRM added all the crossbred cows to either pure Jer or pure Hol RS. Then a third GRM that included all animals of all breeds (i.e., 98,000 animals) was formed. The reason for making 3 different GRMs based on the $3 \mathrm{RS}$ was to ensure that the markers with lower allele frequency, which in turn are assumed to have larger effects, are properly identified and weighted in each situation. This may vary depending on the population of animals: including breed composition and its size.

The phenotypes used as a response variable were DRP on cows obtained from DataGene and DRP on bulls obtained from Interbull. In the analyses where appropriate, breed or sex or country were fitted as fixed effects. In the largest analyses where close to 98,000 animals (bulls and cows) were included in the RS, fixed effects were fitted for up to 8 different groups (countrybreed-sex): such as NZ crossbred cows, NZ Hol cows, NZ Jer cows, CRV Jer bulls, CRV Hol bulls, CRV Red Hol bulls, AU Hol cows, and AU Jer cows (Table 1).

The single trait model was

$$
\mathbf{y}=1 \boldsymbol{\mu}+(\mathbf{X b})+\mathbf{Z g}+\mathbf{e},
$$

where $\mathbf{y}$ is a vector of response variables; $\boldsymbol{\mu}$ is the overall mean, $\mathbf{b}$ is a vector of fixed effects such as country (NZ vs. AU), or sex (bull vs. cow), or breed (Jer, Hol, crossbred, Red Hol, and so on); $\mathbf{X}$ is a design matrix relating $\mathbf{y}$ to country, sex, breed, and so on, depending on the RS as described in Table 2 ; $\mathbf{Z}$ is a design matrix relating records to direct genomic value (DGV) of animals; $\mathbf{g}$ is a vector of $\mathrm{DGV} \sim N\left(\mathbf{0}, \mathbf{G} \sigma_{g}^{2}\right)$, where $\mathbf{G}$ is the GRM and $\sigma_{g}^{2}$ is the genomic variance; and $\mathbf{e}$ is a vector of random residuals $\sim N\left(\mathbf{0}, \mathbf{D} \sigma_{e}^{2}\right)$, where $\sigma_{e}^{2}$ is the residual variance and $\mathbf{D}$ is a diagonal matrix derived as in Garrick et al. (2009) to account for difference in reliability of DRP of cows and bulls assuming that $20 \%$ of the total variance is not explained by marker data.

For the bivariate models, where a separate trait is defined for each country, model 2 was

$\left[\begin{array}{l}\mathbf{y}_{1} \\ \mathbf{y}_{2}\end{array}\right]=\left[\begin{array}{cc}\mathbf{I}_{1} & 0 \\ 0 & \mathbf{I}_{2}\end{array}\right]\left[\begin{array}{l}\boldsymbol{\mu}_{1} \\ \boldsymbol{\mu}_{2}\end{array}\right]+\left[\begin{array}{cc}\mathbf{X}_{1} & 0 \\ 0 & \mathbf{X}_{2}\end{array}\right] \mathbf{b}_{1}+\left[\begin{array}{cc}\mathbf{b}_{1} & 0 \\ 0 & \mathbf{Z}_{2}\end{array}\right]\left[\begin{array}{l}\mathbf{g}_{1} \\ \mathbf{g}_{2}\end{array}\right]+\left[\begin{array}{l}\mathbf{e}_{1} \\ \mathbf{e}_{2}\end{array}\right]$,

where $\mathbf{y}_{1}$ and $\mathbf{y}_{2}$ are the vectors of response variables (i.e., trait 1 is the DRP of AU cows and trait 2 is the DRP of NZ cows or DRP of NZ cows and bulls), $\mathbf{I}_{1}$ and $\mathbf{I}_{2}$ are identity matrices, $\boldsymbol{\mu}_{1}$ and $\boldsymbol{\mu}_{2}$ are the means for
AU cows and NZ cows or bulls, $\mathbf{X}_{1}$ and $\mathbf{X}_{2}$ are design matrices that allocate the response variables $\mathbf{y}_{1}$ and $\mathbf{y}_{2}$ to sex and breed where applicable (e.g., NZ bull or cow, Red Hol or Hol bulls, or both), $\mathbf{b}_{1}$ and $\mathbf{b}_{2}$ are vectors of fixed effects such as sex and breed, $\mathbf{Z}_{1}$ and $\mathbf{Z}_{2}$ are the design matrices that relate DGV to the country of the record, $\mathbf{g}_{1}$ and $\mathbf{g}_{2}$ are the vectors of DGV for country treated as trait ( $\mathrm{NZ}$ and $\mathrm{AU}$ ), and $\mathbf{e}_{1}$ and $\mathbf{e}_{2}$ are vectors of random residuals for $\mathrm{NZ}$ or $\mathrm{AU}$. It was assumed that $\left[\begin{array}{l}\mathbf{g}_{1} \\ \mathbf{g}_{2}\end{array}\right] \sim \operatorname{MVN}(0, \mathbf{G} \otimes \mathbf{T})$, where $\mathbf{T}=\left[\begin{array}{cc}\sigma_{\boldsymbol{g} 1}^{2} & \sigma_{\boldsymbol{g} 12} \\ \sigma_{\boldsymbol{g} 12} & \sigma_{\boldsymbol{g}_{2}}^{2}\end{array}\right]$ is the variance-covariance matrix of country of animals, and $\left[\begin{array}{l}\mathbf{e}_{1} \\ \mathbf{e}_{2}\end{array}\right] \sim \operatorname{MVN}(0, \mathbf{D} \otimes \mathbf{R})$, where $\mathbf{R}=\left[\begin{array}{cc}\mathbf{D} \sigma_{e_{1}}^{2} & 0 \\ 0 & \mathbf{D} \sigma_{e_{2}}^{2}\end{array}\right]$ is the residual variance-covariance matrix with the off-diagonals defined to be 0 , and $\mathbf{D}$ is as defined in model 1 . $M V N$ is multivariate normal distribution, and $\otimes$ is the Kronecker matrix product.

Based on preliminary analyses, the scenarios (Table 2) that gave highest reliabilities for Jer and Hol validation using GBLUP were further assessed by performing EM-Bayes $R$ analyses to test if the addition of AU cows increases the reliability of prediction relative to that observed using NZ animals. The EM-Bayes R analyses were done for set 7 (all NZ animals excluding Hol) and set 8 (adding Jer AU cows) for Jer and set 9 (all NZ animals) and set 10 (adding all AU cows) for Hol. The Bayesian analysis was implemented using in-house software following the computationally efficient method developed by Wang et al. (2016): EM-Bayes R hybrid. The EM-Bayes $\mathrm{R}$ model, which is a univariate model, can be written as

$$
\mathbf{y}=\mathbf{X b}+\mathbf{W} \mathbf{v}+\mathbf{e}
$$

where $\mathbf{W}$ is a design matrix of genotypes and $\mathbf{v}$ is a vector of variant effects, drawn from 4 normal distributions with $N\left(0,0 \sigma_{g}^{2}\right), N\left(0,0.0001 \sigma_{g}^{2}\right), N\left(0,0.001 \sigma_{g}^{2}\right)$, and $N\left(0,0.001 \sigma_{g}^{2}\right)$, where $\sigma_{g}^{2}$ is the additive genetic variance and prior distribution of the proportion of variants per distribution $\mathbf{P} \sim$ Dirichlet $(\boldsymbol{\alpha})$, with $\boldsymbol{\alpha}=[1,1,1,1]$. All other effects are the same as defined in model 1 above.

In the EM-Bayes $\mathrm{R}$ approach, the initial EM phase was set for a maximum of 1,500 iterations and the convergence parameter was set as $1 \times 10^{-7}$. The Bayes $\mathrm{R}$ phase was set to complete 5,000 (50K SNP) or 10,000 iterations (HD SNP). For each trait and model, 5 independent replicated analyses (Markov chain Monte Carlo) were run and checked for convergence. Then DGV for validation bulls were the mean of the 5 rep- 
licates, though the Pearson correlations between DGV from different replicates were above 0.99 in all cases.

\section{Criteria for Comparison of Different Sets or Scenarios}

The DGV predicted from the different sets of reference animals or models, or SNP chips or methods for Hol and Jer validation bulls were used for comparison. The following statistics were assessed for validation bulls:

(1) Squared correlation between DGV and DRP in validation bulls or $\mathrm{R}^{2}$ (proportion of variance in DRP explained by DGV). Then the $\mathrm{R}^{2}$ were divided by the mean reliability of the DRP of the validation bulls to get the adjusted $\mathrm{R}^{2}$ or reliability. By calculating the adjusted $\mathrm{R}^{2}$ we assumed that the correlation between DGV and DRP is through their correlation to the true BV.

(2) The bias of predictions defined as the regression coefficient (b) of DRP of validation bulls on DGV.

When calculating $\mathrm{R}^{2}$ and the bias (b), the number of effective daughters per bull was used as weight in ASReml (Gilmour et al., 2009). The DGV used for validation bulls from the bivariate models were those that correspond to NZ (trait).

\section{RESULTS}

\section{Breed Distribution and Genotypes}

In most cases the clustering of animals using PCA agreed with the 4-letter breed identifier code (e.g., JJFF) in the pedigree data that were used by DataGene. The PCA distribution of animals with purebred breed codes were consistently located within their expected breed groups. However, approximately $5 \%$ of NZ cows with a purebred pedigree code (FFFF or JJJJ) appeared more likely to be crossbred on PCA and $0.6 \%$ of the $\mathrm{F}_{1}$ crossbreds appeared to be closer to purebred. The equivalent proportions for the $\mathrm{AU}$ cows were lower at $0.6 \%$ (designated as purebred when their PCA classified them as crossbred) and $0.3 \%$ (designated as crossbred when their PCA classified them as purebred), which was expected given crossbreeding is much less common in AU compared with NZ. For this study we reallocated cows from $\mathrm{AU}$ and $\mathrm{NZ}$ into 3 main breed groups based on pedigree and the PCA results: (almost; $>\sim 75 \%$ ) pure Hol, (almost; $>\sim 75 \%$ ) pure Jer, and a third category labeled as crossbred. Supplemental Figure S1 (https://doi.org/10.3168/jds.2019-17170) shows the PCA with breed allocations as used in this study.

The PCA of GRM demonstrates that the NZ cows show considerably more genetic diversity than AU cows (Supplemental Figure S1; https://doi.org/10.3168/jds .2019-17170). The diversity in NZ cows is expected because the use of crossbred dairy cows is much more common than in AU. Additionally, in NZ, semen is marketed from crossbred bulls and there is also still a strong influence from locally bred Friesian bulls. The NZ cow population included considerably more crossbreds than the AU cow population ( 17,000 vs. $~ 1,900)$ so the AU crossbred cows were not used in the RS.

\section{Reference and Validation Animal Phenotypes}

Table 1 shows a difference in the mean and standard deviation of $\mathrm{NZ}$ and $\mathrm{AU}$ cows and also between bulls (NZ DRP) and cows (NZ DRP) for all trait phenotypes. The difference between NZ and AU cows was higher for MY compared with the other traits. The mean difference for DRP of MY traits between bulls and cows is to some extent due to the difference in birth year of the animals (which is reflected in the genetic trend) and is also due to the fact that the DRP for the 2 sexes are from 2 different sources (MACE for bulls and DRP processed by DataGene for cows).

\section{Genomic Heritability and Genetic Correlation Between NZ and AU}

Genomic heritability estimates for MY traits based on the performance of cows in NZ and AU are shown in Table 3. The heritability of MY traits was higher in AU cows than in NZ cows for both Hol and Jer. The use of the HD SNP chip explained more of the variance for all the traits than the 50K SNP chips. This was more obvious in AU Hol cows than in NZ Hol cows, where the HD SNP chip explained between 3 to $4 \%$, more variation than the 50K SNP chip. With regard to the differences among traits, the heritability of MY was higher than both protein (PY) and fat yield (FY) for both breeds. The lowest heritability was observed for PY in Hol and for FY in Jer in both countries.

Genetic correlations (all traits) in Hol breed between performance in NZ and $\mathrm{AU}$ cows were higher by 0.04 to 0.05 when the HD SNP chip was used than when the 50K SNP chips was used (Table 4). On the other hand, in Jer the genetic correlations between NZ and AU cows for all traits were less affected by the density of the SNP chip (Table 4). The highest genetic correla- 
Table 3. Heritability estimates $( \pm \mathrm{SE})$ for milk yield traits when recorded in New Zealand (NZ) or Australia (AU) cows using $50 \mathrm{~K}$ and high-density (HD) genotypes for Holstein and Jersey cows

\begin{tabular}{lccccc}
\hline & \multicolumn{2}{c}{$50 \mathrm{~K}$} & & \multicolumn{2}{c}{$\mathrm{HD}$} \\
\cline { 2 - 3 } \cline { 5 - 6 } Trait & $\mathrm{AU}$ & $\mathrm{NZ}$ & & $\mathrm{AU}$ & $\mathrm{NZ}$ \\
\hline Holstein & & & & \\
$\quad$ Milk yield & $0.32 \pm 0.01$ & $0.31 \pm 0.01$ & & $0.36 \pm 0.01$ & $0.34 \pm 0.01$ \\
$\quad$ Fat yield & $0.24 \pm 0.01$ & $0.24 \pm 0.01$ & & $0.28 \pm 0.01$ & $0.26 \pm 0.01$ \\
$\quad$ Protein yield & $0.21 \pm 0.01$ & $0.22 \pm 0.01$ & & $0.24 \pm 0.01$ & $0.25 \pm 0.01$ \\
Jersey & $0.51 \pm 0.01$ & $0.42 \pm 0.02$ & & $0.52 \pm 0.01$ & $0.45 \pm 0.02$ \\
$\quad$ Milk yield & $0.28 \pm 0.01$ & $0.22 \pm 0.02$ & & $0.29 \pm 0.01$ & $0.22 \pm 0.02$ \\
$\quad$ Fat yield & $0.33 \pm 0.01$ & $0.24 \pm 0.02$ & & $0.35 \pm 0.02$ & $0.27 \pm 0.02$ \\
Protein yield & &
\end{tabular}

tions between $\mathrm{NZ}$ and $\mathrm{AU}$ was observed for $\mathrm{MY}$ in $\mathrm{Hol}$ and for FY in Jer.

\section{GP for NZ Bulls Using Different NZ-Only RS}

Although the main objective of this study was to determine the benefit of adding $\mathrm{AU}$ cows to a reference that only included NZ animals, the increase in reliability due to the expansion of the NZ RS sequentially from purebred cows to all NZ animals (purebred bulls and cows and crossbred cows) is first presented for Jer (Figure 1) and Hol (Figure 3) validation bulls.

Figure 1 shows the adjusted $\mathrm{R}^{2}$ for Jer validation bulls when all NZ purebred Jer cows (set 1), purebred Jer cows and bulls (set 4), pure Jer and crossbred and Jer bulls (set 7), and all NZ animals including Hol cows and bulls (set 9) are used as RS. First, Figure 1 shows that the addition of NZ Jer bulls to the RS that only included NZ Jer cows increased the $\mathrm{R}^{2}$ by $0.13,0.10$, and 0.16 for MY, FY, and PY, respectively (Figure 1). For the RS that only included NZ Jer cows and bulls (set 4), adding all the crossbred cows (set 7) increased the $\mathrm{R}^{2}$ only marginally.

For Jer validation bulls, the use of all NZ animals (Jer, Hol, and crosses) results in the highest adjusted $\mathrm{R}^{2}$ for $\mathrm{FY}$ and MY, but not for PY. The increase is more obvious for FY when the HD SNP chip was used. On average for the 3 traits, the use of all NZ animals with HD SNP resulted in a 1 percentage point decrease in reliability compared with the set that did not include Hol cows and bulls. The average decrease is because the reliability for PY decreased from $0.45(50 \mathrm{~K})$ and 0.46 (HD) before Hol cows are included to 0.40 (50K) and 0.41 (HD) after including them (Figure 1). Figure 2 shows the regression coefficients of DRP on DGV, which are all below 1.0, and the deviation from 1.0, or bias, increased with the inclusion of Hol cows in the RS. In fact, regression coefficients that were closer to 1.0 were obtained when using bulls only (results not shown) or Jer cows and bulls and crossbred cows were used in the reference, so regression values for other scenarios are not presented.

Figure 3 shows the adjusted $\mathrm{R}^{2}$ for validation $\mathrm{Hol}$ bulls when all NZ purebred Hol cows (set 1), purebred Hol cows and bulls (set 4), pure Hol and crossbred and Hol bulls (set 7), and all NZ animals including Jer cows and bulls (set 9) are used in the RS. The addition of Hol bulls to the RS that only included NZ Hol cows resulted in the biggest gain in $\mathrm{R}^{2}$ for Hol validation bulls (Figure 3). The highest increase was observed for PY where the adjusted $\mathrm{R}^{2}$ increased from 0.06 (HD SNP chip) and 0.07 (50K SNP chip) when only NZ cows were used to 0.40 (HD SNP chip) and 0.40 (50K SNP chip) when bulls are added to the RS (set 4). Adding crossbred cows (set 7) to a RS (set 4) that only included Hol bulls and cows from NZ increased

Table 4. Genetic correlations ( \pm SE) between performance in Australia (AU) and New Zealand using a genomic relationship matrix constructed from 50K and high-density (HD) genotypes for Holstein and Jersey cows

\begin{tabular}{lccccc}
\hline & \multicolumn{2}{c}{ Holstein } & & \multicolumn{2}{c}{ Jersey } \\
\cline { 2 - 3 } \cline { 5 - 6 } Trait & $50 \mathrm{~K}$ & HD & & $50 \mathrm{~K}$ & HD plus XT $^{1}$ \\
\hline Milk yield & $0.78 \pm 0.02$ & $0.83 \pm 0.02$ & & $0.75 \pm 0.04$ & $0.78 \pm 0.04$ \\
Fat yield & $0.71 \pm 0.03$ & $0.76 \pm 0.03$ & & $0.81 \pm 0.06$ & $0.80 \pm 0.04$ \\
Protein yield & $0.60 \pm 0.03$ & $0.64 \pm 0.03$ & & $0.69 \pm 0.06$ & $0.70 \pm 0.06$ \\
\hline
\end{tabular}

${ }^{1} \mathrm{XT}=$ selected SNP panels. 
the $\mathrm{R}^{2}$ by $0.11,0.02$, and 0.09 , for MY, FY, and PY, respectively, when HD SNP chip is used. When the 50K SNP chip was used the increase in adjusted $\mathrm{R}^{2}$ was $0.11,0.04$, and 0.09 , for MY, FY, and PY, respectively (Figure 3).

The results for Hol validation bulls shows that either using all animals, including Jer bulls and cows (set 9), or set 7 , results in higher adjusted $\mathrm{R}^{2}$ than the other scenarios. In the Hol bull validation, MY is predicted with higher reliability than both FY and PY. Figure 4 shows the regression coefficient for sets that only include NZ animals. The RS 4 where Hol bulls and cows are used is relatively less biased than all the other scenarios; therefore, regression values for all other scenarios except those in Figure 4 are not presented in the Results section.

\section{GP for NZ Bulls When Adding AU Cow Populations}

Purebred Cow $R S$. Figure 5 shows the adjusted $\mathrm{R}^{2}$ when NZ and AU Jer cows are included in the RS of univariate (set 2) and bivariate models (set 3) to predict Jer validation bulls, the results are compared with a set where only NZ Jer cows are used. The baseline reliability using NZ Jer cows, as shown in Figure 1, is also included in Figure 5 for clarity. Adding AU cows results in a modest increase in $R^{2}$ because the reliability levels when only NZ cows are used are relatively high despite the small number NZ Jer cows (Figure 5). The increase in reliability was the highest $(\sim 15$ percentage point increase) for MY using the HD SNP chip in a univariate model. The maximum increase in $\mathrm{R}^{2}$ by adding AU cows was 7 percentage points for FY (50K SNP chip using a univariate model) and PY (HD SNP chip using bivariate model).

The $\mathrm{R}^{2}$ statistics obtained when only NZ cows, and $\mathrm{NZ}$ and AU cows are used to predict Hol validation bulls in univariate and bivariate models are shown in Figure 6 . The addition of AU cows to a set that only includes $\mathrm{NZ}$ cows more than doubled the $\mathrm{R}^{2}$ for Hol validation bulls for MY and PY when either the 50K or HD SNP chips were used. The $\mathrm{R}^{2}$ for FY almost doubled when the performance of cows in AU and NZ were considered to be the same trait. For all traits, the inclusion of $\mathrm{AU}$ cow data in univariate models was better than, or as good as, the bivariate model. In particular, the bivari-

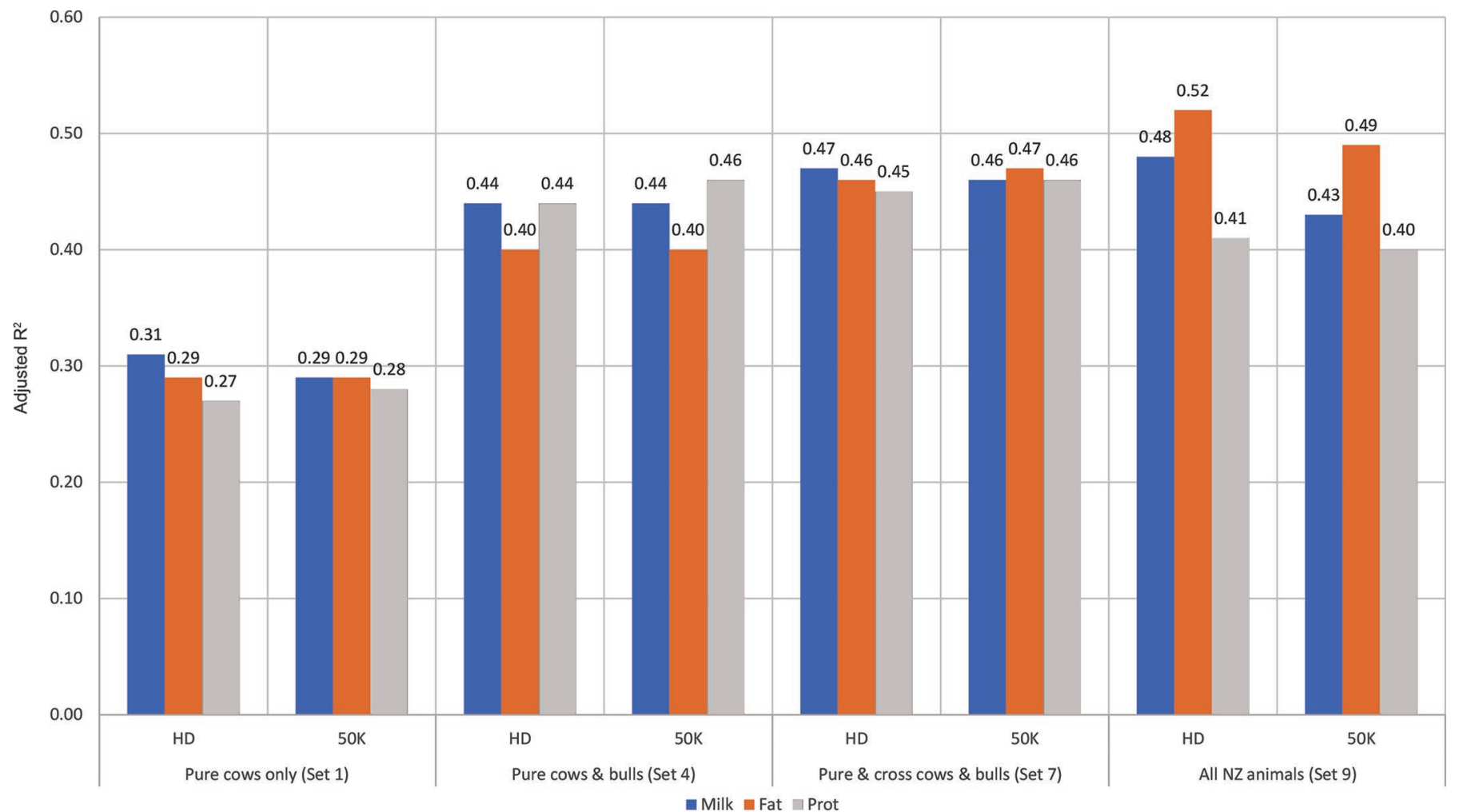

Figure 1. Adjusted $\mathrm{R}^{2}$ (adjusted coefficient of determination) of direct genomic values for Jersey validation bulls with deregressed proofs in New Zealand (NZ) using NZ animals in the genomic BLUP reference set. HD = high density; Prot = protein. 


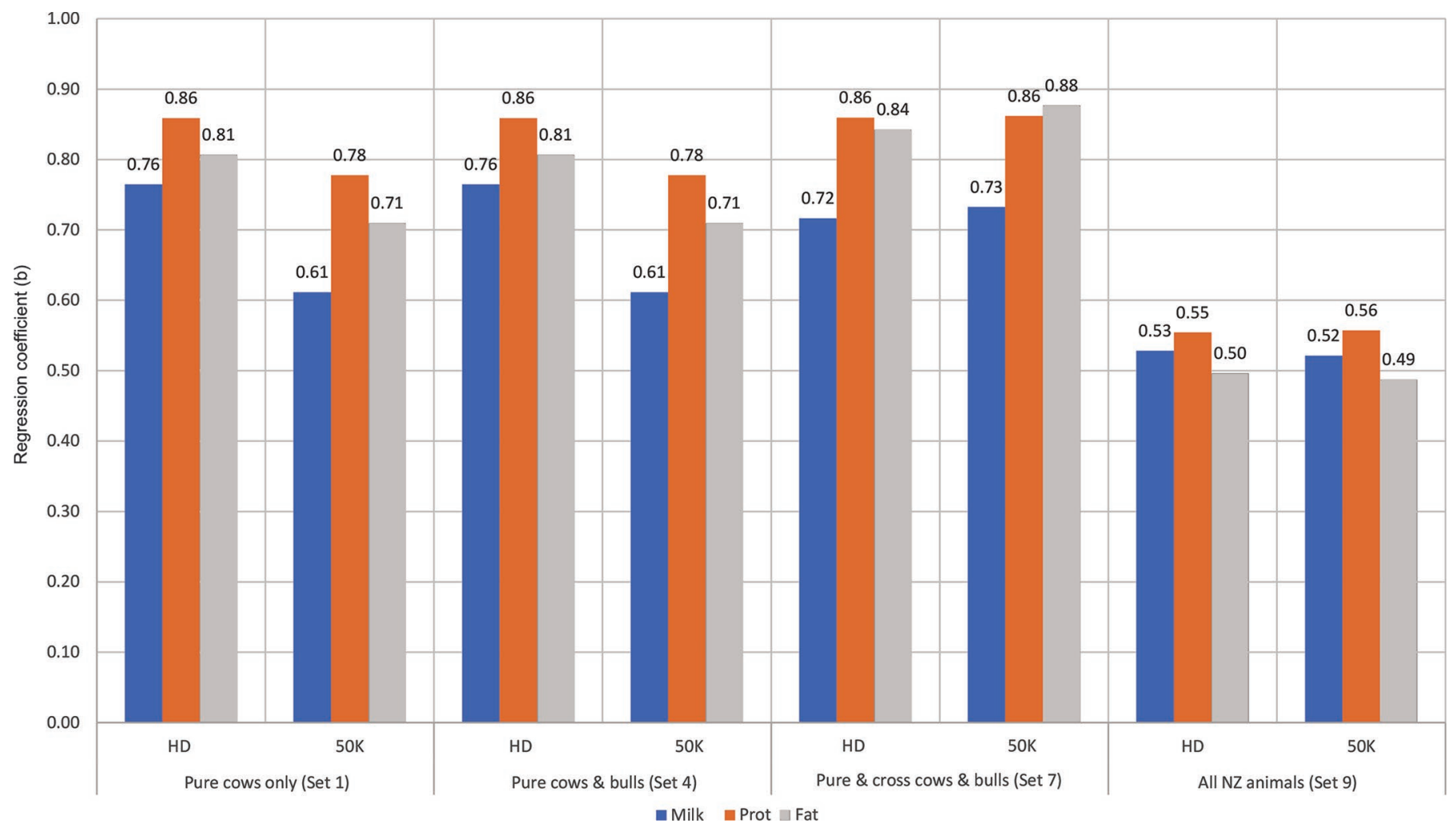

Figure 2. Regression coefficient of deregressed proofs on direct genomic values for Jersey validation bulls in New Zealand (NZ) using NZ animals in the genomic BLUP reference set. HD = high density; Prot = protein.

ate model underperformed for PY, where the proportion of variance explained by GRM was slightly lower in AU cows than in NZ cows (Table 3).

Purebred Cow and Bull RS. Figure 7 shows the increase in adjusted $\mathrm{R}^{2}$ by adding $\mathrm{AU}$ Jer cows to the NZ Jer cow and bull RS (set 5) in univariate and bivariate models (set 6). Overall, for Jer validation bulls, the bivariate models and the 50K SNP chip gave a slightly lower reliability than the single trait models with the HD SNP chip. The addition of AU cows to the RS that is based on NZ cows and bulls in univariate models increased the $\mathrm{R}^{2}$ by $0.10,0.09$, and 0.05 for MY, $\mathrm{FY}$, and PY, respectively, in the univariate model using the HD SNP chip.

Figure 8 shows that adding AU Hol cows to a RS that included Hol cows and bulls, increased $R^{2}$ by 0.05 to 0.07 for MY or FY. The increase for PY was slightly lower at 0.03 to 0.05 . No difference was observed between the SNP chips, but there was some tendency for the $\mathrm{R}^{2}$ from the bivariate model to be slightly higher than the single trait model.

All-Breed and All-Country $R S$. Table 5 shows the $\mathrm{R}^{2}$ for Jer validation bulls when the following $\mathrm{RS}$ were used in GBLUP and EM-Bayes R: set 7 (NZ Jer cow and bull and crossbred cows), set 8 (set 7 plus AU cows), set 9 (all NZ animals including Hol), and set 10 (all-breed and all-country set). Adding NZ-only Hol cows (set 9) or Hol cows from both countries (set 10) to a reference that included NZ Jer cows and bulls and NZ crossbreds (set 7 ) or set 8 (all Jer animals and crossbred cows) results in small decrease in $\mathrm{R}^{2}$ for validation Jer bulls. Adding AU Jer cows (set 8) increased $\mathrm{R}^{2}$ by 0.06 (HD) to $0.07(50 \mathrm{~K})$ when GBLUP and $0.05(50 \mathrm{~K})$ to 0.07 (HD) when EM-Bayes $\mathrm{R}$ is used compared with set 7 .

Table 6 shows the $\mathrm{R}^{2}$ for Hol validation bulls using set 7 and 8 based on GBLUP only and set 9 and 10 based on GBLUP and EM-Bayes R. In the case of Hol validation bulls, the addition of all AU cows including Jer cows gave similar $\mathrm{R}^{2}$ when GBLUP (HD or $50 \mathrm{~K}$ SNP chip) was used. The use of EM-Bayes $\mathrm{R}$ averaged over the 3 traits increased the $\mathrm{R}^{2}$ by 1 and 2 percentage points when 50K SNP and HD SNP chip were used, respectively, (Table 6) relative to the same set using GBLUP.

\section{Effect of Method or SNP Chip Density on $R^{2}$}

Overall the use of HD did not improve the $\mathrm{R}^{2}$ compared with using the 50K SNP chip when either GBLUP 


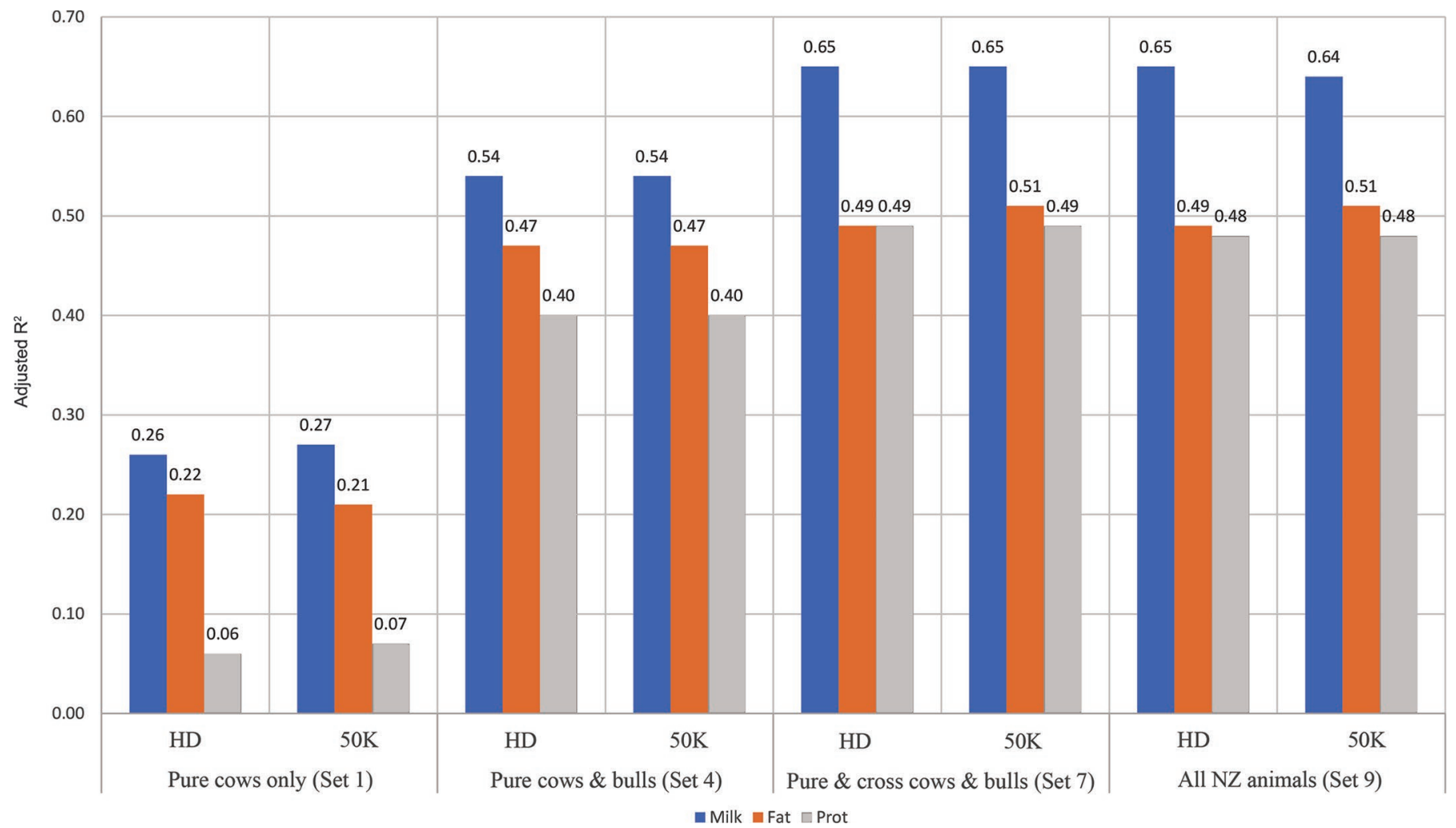

Figure 3. Adjusted $\mathrm{R}^{2}$ (adjusted coefficient of determination) of direct genomic values for validation Holstein bulls with deregressed proofs in New Zealand (NZ) using NZ animals in the genomic BLUP reference set. HD = high density; Prot = protein.

or EM-Byes $\mathrm{R}$ methods were used. The 2 exceptions were a small but consistent increase in the adjusted $\mathrm{R}^{2}$ for Jer validation bulls when using all NZ animals (Figure 1), and when NZ and AU animals were used in the RS (Table 5). The EM-Bayes R on average gave slightly higher $\mathrm{R}^{2}$ than GBLUP using HD SNP chip or 50K SNP chip (Tables 5 and 6). Using EM-Bayes R produced higher $\mathrm{R}^{2}$ (1 to $2 \%$ ) for MY and FY (Table 6 ) in Hol (set 9 and 10) and FY (2 to 7\%; Table 5) in Jer (in set 8 and 10).

\section{DISCUSSION}

The main objective of this study was to determine the benefit of adding $\mathrm{AU}$ cows to a RS that only included NZ animals. Adding AU cows increased the reliability of GP for all traits. It was clear that the benefit of adding AU cows was more significant when the RS in NZ was smaller (e.g., only purebred cows). As the size of the NZ RS was increased by including bulls and crossbred cows, the increase in $\mathrm{R}^{2}$ by adding AU cows decreased. This reinforces the observation that GP benefits from sharing of cow or bull genotypes and phenotypes if the size of the RS size is numerically small (e.g., Schöpke and Swalve, 2016). The results from this study show that considering only sharing cow genotypes mimics a scenario where genomic evaluations do not have progeny-tested bulls that can be used as a RS, such as genomic evaluations for new novel or expensive to measure traits (de Haas et al., 2012; Pryce et al., 2012).

An interesting observation from this study is that for Jer validation bulls, adding 8,932 AU Jer cows improved the reliability (Figure 7) more than adding about 17,000 crossbred cows from NZ to the RS (Table $5)$. On the other hand, in the case of Hol validation bulls, the difference in terms of increasing $\mathrm{R}^{2}$ by adding over 50,000 AU Hol cows (Table 6) or adding about 17,000 crossbred cows from NZ was very small (Figure 8). The close relationship among animals of the Jer breed in NZ and AU (e.g., as observed by Howard et al., 2015) and possibly because a much higher proportion of crossbred cows were more closely related to Hol than to Jer could partly explain this result. Furthermore, in addition to having similar genotypes, the production environments in NZ and AU are more similar (i.e., a higher proportion of pasture fed) in Jer herds than in Hol herds (Haile-Mariam et al., 2015). 
Gains in reliability due to adding cows to the RS have been reported in the literature, where it is noted that the gains were higher if the bull RS is smaller and decrease with the size of the bull RS (Cooper et al., 2015; Su et al., 2016; Schöpke and Swalve, 2016). For example, when only bulls were used for validation, Cooper et al. (2015) observed a 0.4 percentage point increase when 30,852 cows were added to a RS that included 21,883 Hol bulls. The gains in reliability were higher (i.e., 4\%) when cows were used as the validation population. In this study, as we used bulls only for validation, the overall gains in $\mathrm{R}^{2}$ are expected to be underestimated if the addition of cow data actually increases the reliability of prediction for cows more than for bulls, as was observed by Cooper et al. (2015). The trait most affected by this is PY, where the correlation between bull and cow DRP is low, particularly in the NZ Hol population (at 0.60 with $50 \mathrm{~K}$ SNP and 0.61 with HD SNP, result not shown elsewhere). For MY and FY in Hol and for all traits in Jer, the correlation between bull and cow DRP was higher than 0.75. Note that correlations of below 1.0 between bull and cow data for the same trait were also reported by Calus et al. (2013) and Jenko et al. (2017) in dairy cattle data and by Porto-Neto et al. (2015) in beef cattle data. It is interesting to verify and understand this and its implication on the reliability of GP. Part of the reason for the below 1.0 correlation in the current study could be due to the use of data from different sources DRP from MACE on bulls and DRP from AU national genetic evaluation on cows.

In this study adding cow data from another country with similar genotypes and a comparable production environment, while including different breed groups of cows from within the same country, increased $\mathrm{R}^{2}$ relative to only using a bull RS for MY traits that have medium to high heritability. The differences observed in this study in $\mathrm{R}^{2}$ among MY traits (Tables 5 and 6 ) could be related to the difference in genomic heritability (Table 3). The reliabilities were lower, for example, for PY in the Hol validation set and the benefit of adding AU cows was also lower, reflecting the lower genomic correlation between performance in NZ and AU (Table 4). Our attempt to test the benefit of adding AU cows for low heritability traits, such as fertility, was not successful, as was also observed by Jenko et al. (2017). For fertility adding AU Hol cows to a RS that only included NZ Hol cows showed an increase in $\mathrm{R}^{2}$

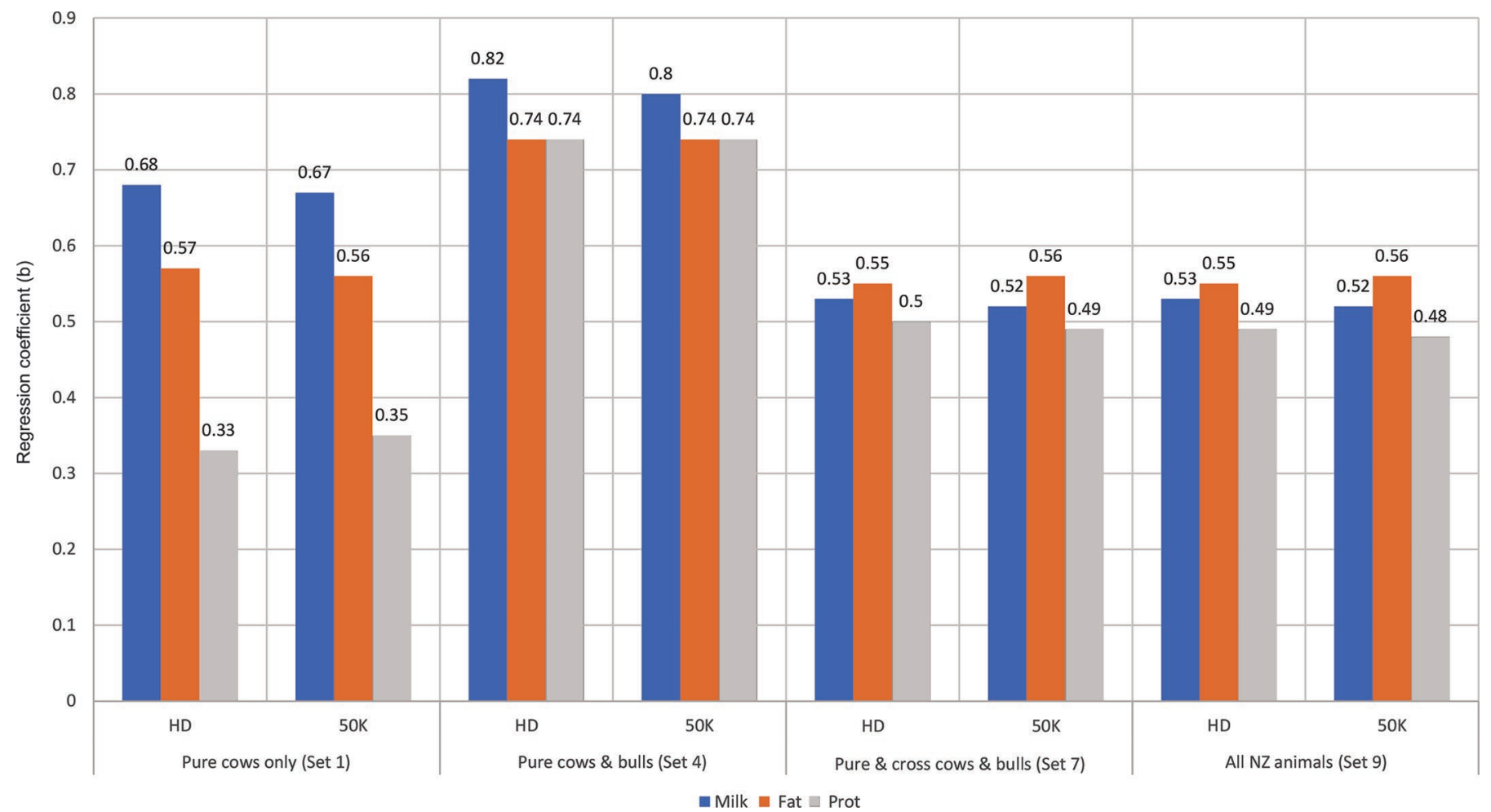

Figure 4. Regression coefficient of deregressed proofs on direct genomic values of Holstein validation bulls in New Zealand (NZ) using NZ animals in the genomic BLUP reference set. HD = high density; Prot = protein. 
from 0.11 to 0.25 in a single trait model and to 0.28 in a bivariate model (results not shown elsewhere). However, there was no benefit of adding AU cows when the NZ RS included about 6,500 cows and 4,500 Hol bulls with fertility data. This result suggests that the benefit of sharing cows is lower for traits with low heritability if there are progeny-tested bulls that could be included in the RS. However, if there are no or fewer bulls with phenotypes, a moderate increase in reliability, even for lowly heritable traits, may be possible.

When sharing genotype and phenotype data between countries, the performance in each country can either be treated as the same trait, or as correlated trait. The results showed that when only cows were included in the RS, a single trait model was better than the bivariate model. We observed that a bivariate model was slightly better than a single trait model for PY and FY, when Hol bulls and cows from NZ and Hol cows from AU are used (Figure 8). This suggests that the condition for the bivariate model to be better than the univariate model is limited, as the maximum contribution from a correlated trait depends on the squared correlation $\left(\mathrm{R}^{2}\right)$ between the 2 countries (i.e., traits). For example, for PY, when the genetic correlation between $\mathrm{NZ}$ and $\mathrm{AU}$ is $0.61(50 \mathrm{~K})$ to 0.64 (HD) in Hol (Table 3 ), the maximum that the AU cow data can contribute to the reliability of DGV for NZ animals is $0.37(50 \mathrm{~K})$ and 0.41 (HD). The benefit of adding AU cows to a RS that includes NZ bulls, and purebred and crossbred cows was tested using a single and bivariate model; the single trait model was at least as good as the bivariate model (results not shown).

The deviation from 1 of the regression coefficients of DRP on DGV shows the extent of inflation in each scenario. The degrees of inflation when data from NZ were used (Figures 2 and 4 ) were similar to values observed in NZ (Winkelman et al., 2015) and for Nordic Jer cattle, where cows and bulls were included in the RS (Gao et al., 2015). The levels of overestimation observed in the current study are similar to those observed by van den Berg (2016) who used French and Danish data comprising several breeds that included Jer and Hol. Regression values closer to 1.0 (i.e., little to no bias) were obtained when only bull data were included in the RS. For example, when only data from bulls were used, the regression values were 0.86 to 1.1

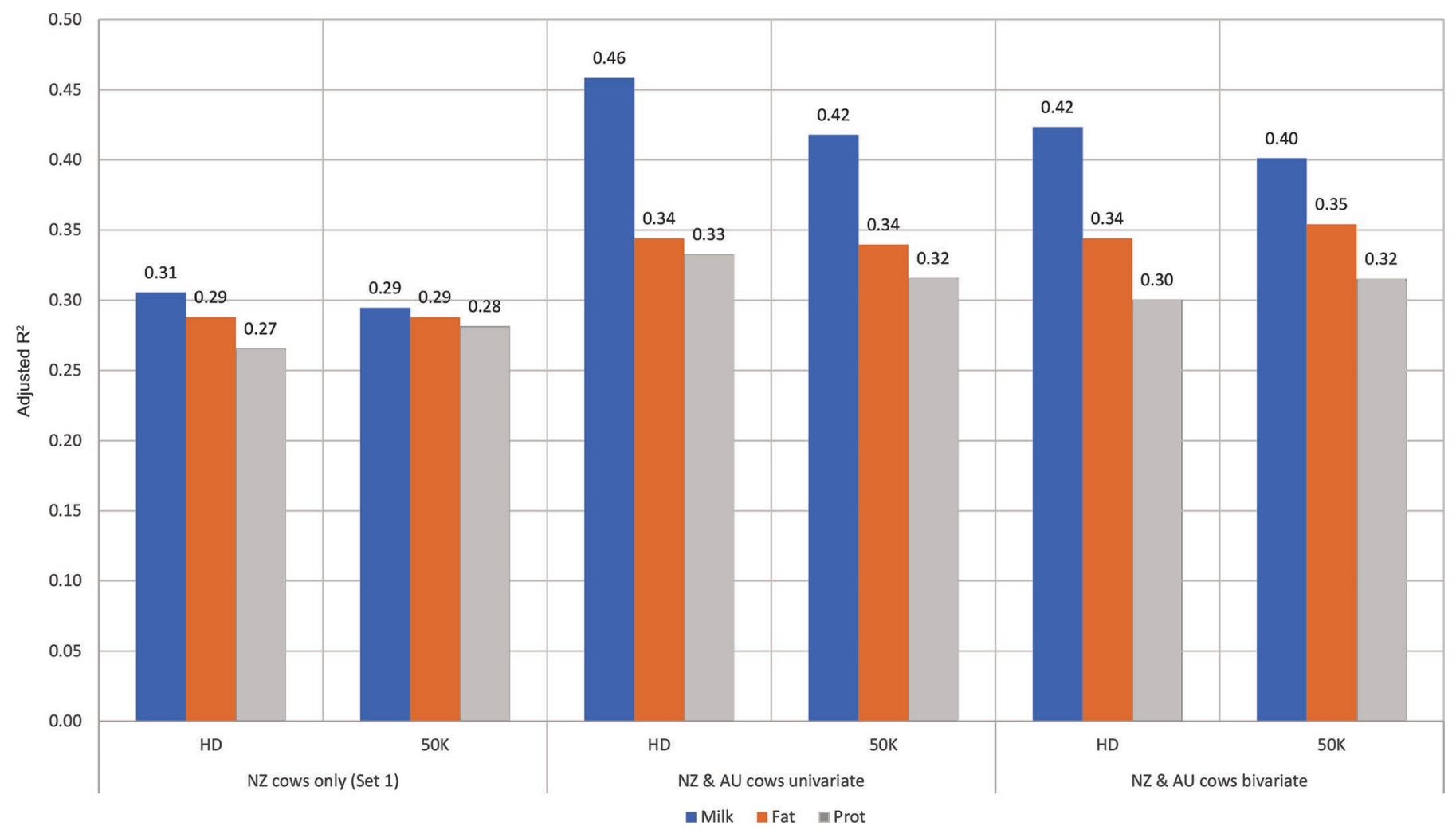

Figure 5. Adjusted $\mathrm{R}^{2}$ (adjusted coefficient of determination) of direct genomic values for validation Jersey bulls with deregressed proofs in New Zealand (NZ) when NZ and Australian cows are included in the genomic BLUP reference set. HD = high density; Prot = protein. 
for Jer and slightly lower at 0.70 to 0.82 for Hol validation bulls (results not included). The reason for the larger bias observed in this study is the difference in variances and means (Table 2) when expanding the RS to include data from different countries, breeds, and sexes. Although bias was reduced when using bulls as a RS, adding the cow data (both NZ and AU cows) increased the adjusted reliability by up to $11 \%$ for Hol and Jer validation bulls (results not shown) compared with using bulls only in the RS.

The genomic heritabilities in the current study were similar to those assumed when calculating genetic evaluations for MY in Jer but overall slightly lower for the other traits (Table 3). The slightly higher estimates, particularly for Hol when using the HD SNP chip, suggests that a denser SNP panel captures more of the genetic variation than the 50K SNP (Table 3). Unfortunately, this did not equate to increased prediction of reliability, as only a small increase occurred in the adjusted $\mathrm{R}^{2}$ when the HD SNP chip was used. This is perhaps because the level of imputation error is higher in the HD SNP chip than the 50K chip (Erbe et al., 2012), or the HD SNP chip may be better at esti- mating the polygenic effect rather than estimating the QTL effects (e.g., van den Berg et al., 2016). By adding selected sequence variants to 50K SNP chip, van den Berg et al. (2016) estimated a higher heritability as well as a higher reliability compared with using all variants for validation bulls for MY traits.

In this study for Jer validation bulls, the observation that the addition of Hol data into the RS did not improve the adjusted $R^{2}$ agrees with the result of van den Berg et al. (2016), but did not agree with Erbe et al. (2012) and Hayes et al. (2009). The reason for a slightly lower reliability when including Hol data could be that the addition causes the data to be strongly dominated by Hol, which results in reduced reliability (van den Berg et al., 2016). However, for Hol validation bulls, the all-breed (set 10) was slightly better, or as good as set 8 , which suggests that for a practical application an all-breed genomic evaluation may be preferable, as prediction for both purebreds and crosses can be produced from one analysis.

The estimates of genetic correlations between NZ and AU cows using genotype data for the same traits (Table 4) are close to those estimated by Interbull for MY in

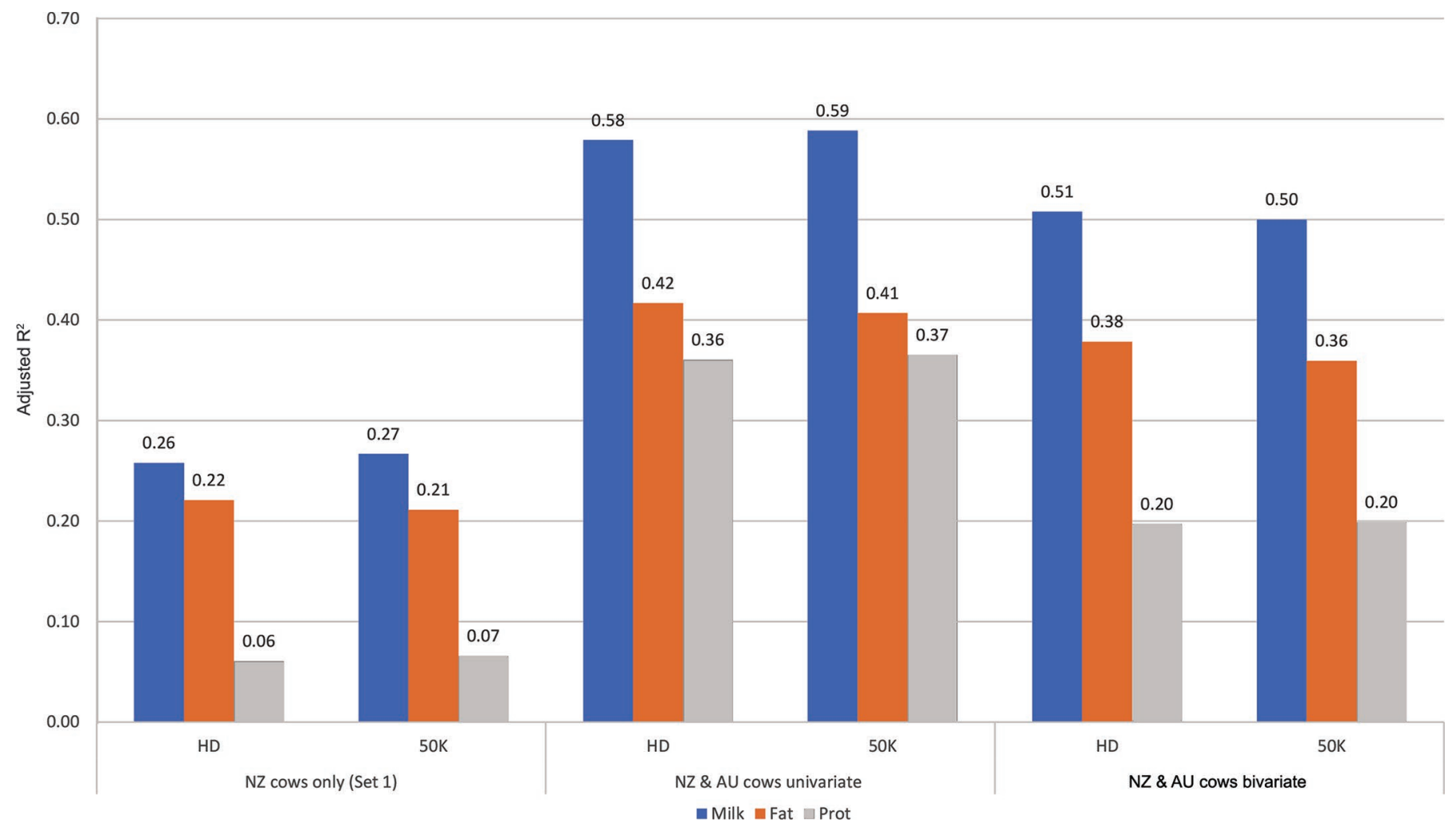

Figure 6. Adjusted $\mathrm{R}^{2}$ (adjusted coefficient of determination) of direct genomic values for validation Holstein bulls with deregressed proofs in New Zealand (NZ) when NZ and Australian cows are included in the genomic BLUP reference set. HD = high density; Prot = protein. 
Hol and for FY in Jer based on bulls with daughters in the 2 countries using pedigree relationships. According to Interbull (2018) the genetic correlations between NZ and $\mathrm{AU}$ are $0.83,0.84$, and 0.81 in the Jer breed and $0.84,0.83$, and 0.81 in the Hol breed for MY, FY, and $\mathrm{PY}$, respectively. The estimates for PY, in particular in Hol when the 50K SNP chip was used, are lower (Table 4) than the Interbull estimates. The slightly lower genetic correlation using marker data, compared with that based on progeny performance of the same sires in the 2 countries, could be due to differences in the genotypes of cows (e.g., Wientjes et al., 2017) used in the 2 countries in addition to $\mathrm{G} \times \mathrm{E}$. Hayes et al. (2017) reported slightly higher genetic correlations between the United States and AU for the Hol breed compared with those estimated by Interbull using genotyped bulls that have performance data of daughters in the United States and AU. The slightly higher genetic correlation between NZ and AU cow data when using HD SNP chip compared with 50K (Table 4), which is observed in Hol data, agrees with Wientjes et al. (2018).

In this study we tested 2 SNP chips and 2 GP methods using a single breed as well as multibreed RS and we also selected validation bulls that do not have their sires and dams in the RS. We expected that a denser SNP chip (de Roos et al., 2009) and a GP method that assumes non-normal prior would improve prediction reliabilities (Erbe et al., 2012; Wang et al., 2016). The performance of the denser SNP chip was no better than the $50 \mathrm{~K}$ chip, and EM-Bayes R was only slightly better than GBLUP. We further assessed the performance of the 2 methods by dividing the Hol validation bulls into those that were first tested in NZ (and therefore possibly had higher relationships with the NZ cow population) and the rest (bulls first tested elsewhere, which was predominantly in the Netherlands) when the RS included all animals (set 10). The gains in adjusted $\mathrm{R}^{2}$ were higher using EM-Bayes R compared with GBLUP in bulls first tested elsewhere compared with those first tested in NZ. The increase in adjusted $\mathrm{R}^{2}$ from $\mathrm{HD}$ GBLUP to EM-Bayes $\mathrm{R}$ was 1 to 2 percentage points in bulls first tested in NZ but higher at 3 percentage points in bulls first tested elsewhere (results not shown). Adding AU cows increased reliability of validation bulls first tested elsewhere by up to 6 percentage points compared with only 2 to 3 percentage points for

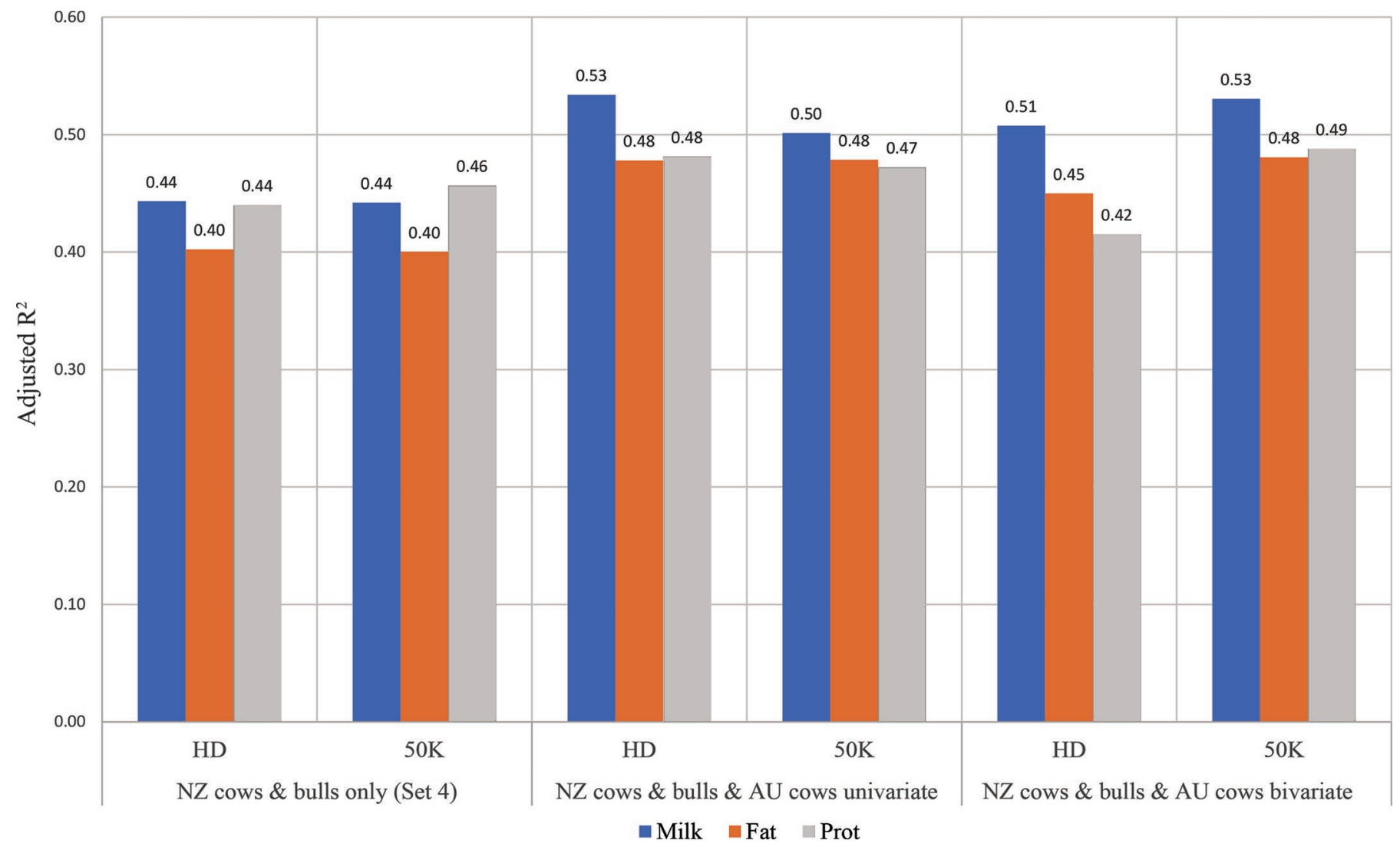

Figure 7. Adjusted $\mathrm{R}^{2}$ (adjusted coefficient of determination) of direct genomic values of Jersey validation bulls with deregressed proofs in New Zealand (NZ) when Jersey cows and bulls from NZ and Jersey cows from Australia are included in the genomic BLUP reference set. HD $=$ high density; Prot $=$ protein. 


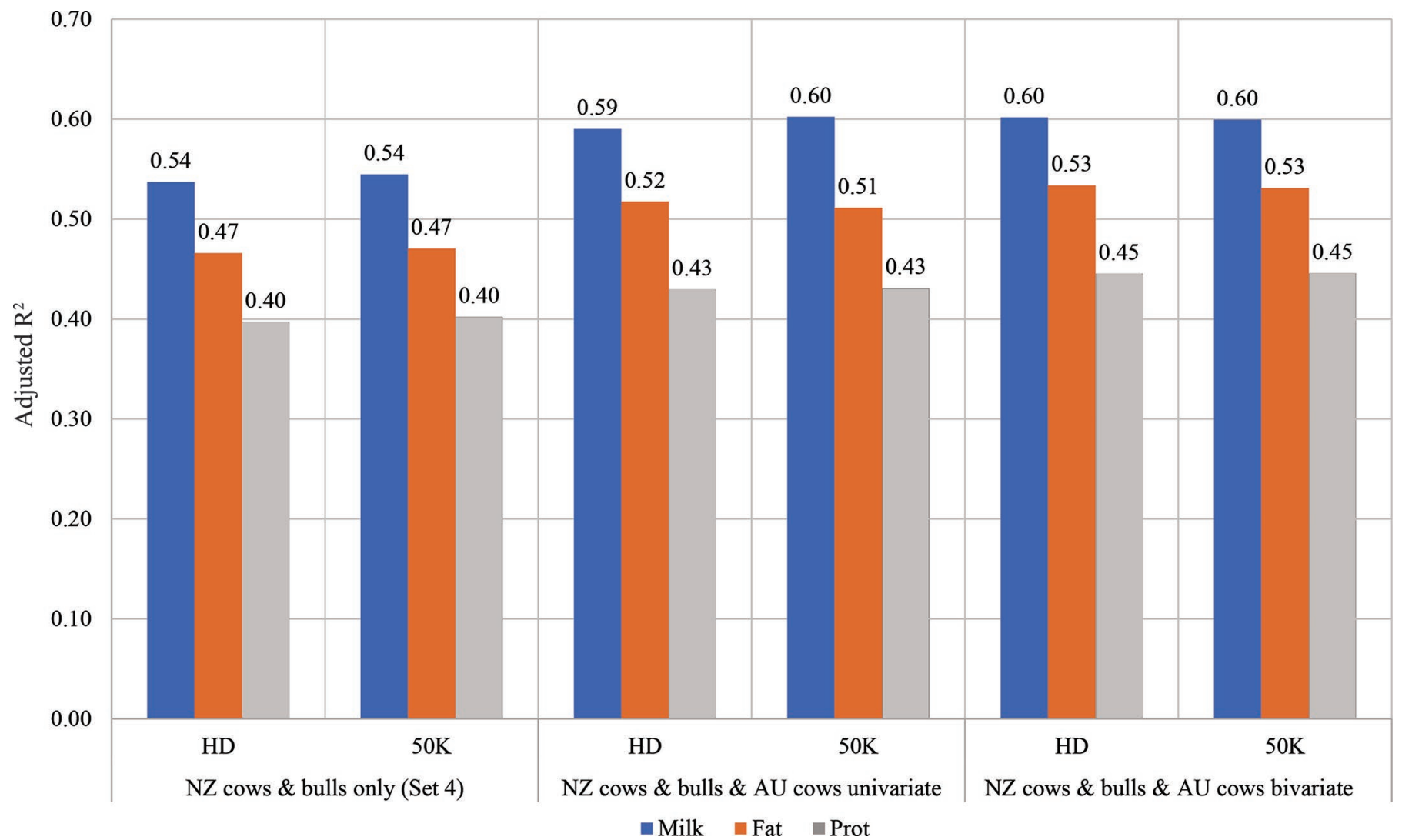

Figure 8. Adjusted $\mathrm{R}^{2}$ (adjusted coefficient of determination) of direct genomic values for validation Holstein bulls with deregressed proofs in New Zealand (NZ) when Holstein cows and bulls from NZ and Holstein cows from Australia (AU) are included in the genomic BLUP reference set. $\mathrm{HD}=$ high density; Prot $=$ protein .

Table 5. Adjusted $\mathrm{R}^{2}$ (squared correlation between direct genomic value and deregressed proofs) for Jersey validation bulls for milk yield traits when using different reference sets, 2 methods [genomic BLUP (GBLUP) vs. expectation maximization (EM)-Bayes R], and 2 SNP chips [high-density (HD) vs. 50K]

\begin{tabular}{|c|c|c|c|c|c|}
\hline \multirow[b]{2}{*}{ Ref set ${ }^{1}$} & \multirow[b]{2}{*}{ Trait } & \multicolumn{2}{|c|}{ GBLUP } & \multicolumn{2}{|c|}{ EM-Bayes R } \\
\hline & & HD & $50 \mathrm{~K}$ & HD & $50 \mathrm{~K}$ \\
\hline \multirow[t]{4}{*}{7} & Milk yield & 0.47 & 0.46 & 0.47 & 0.48 \\
\hline & Fat yield & 0.46 & 0.47 & 0.55 & 0.53 \\
\hline & Protein yield & 0.45 & 0.46 & 0.46 & 0.46 \\
\hline & Average & 0.46 & 0.46 & 0.49 & 0.49 \\
\hline \multirow[t]{4}{*}{8} & Milk yield & 0.56 & 0.54 & 0.53 & 0.53 \\
\hline & Fat yield & 0.53 & 0.53 & 0.60 & 0.58 \\
\hline & Protein yield & 0.51 & 0.49 & 0.49 & 0.49 \\
\hline & Average & 0.53 & 0.52 & 0.54 & 0.53 \\
\hline \multirow[t]{4}{*}{9} & Milk yield & 0.48 & 0.43 & 0.47 & 0.43 \\
\hline & Fat yield & 0.52 & 0.49 & 0.54 & 0.55 \\
\hline & Protein yield & 0.41 & 0.40 & 0.40 & 0.39 \\
\hline & Average & 0.47 & 0.44 & 0.47 & 0.46 \\
\hline \multirow[t]{4}{*}{10} & Milk yield & 0.55 & 0.51 & 0.54 & 0.49 \\
\hline & Fat yield & 0.56 & 0.55 & 0.58 & 0.58 \\
\hline & Protein yield & 0.47 & 0.48 & 0.44 & 0.44 \\
\hline & Average & 0.52 & 0.51 & 0.52 & 0.50 \\
\hline
\end{tabular}

${ }^{1}$ Reference (Ref) set 7 includes New Zealand (NZ) Jersey cows and bulls and crossbred cows, and set 8 includes Jersey cows from Australia (AU). Set 9 includes all NZ animals, and set 10 includes set 9 plus AU Jersey and Holstein cows. 
Table 6. Adjusted $\mathrm{R}^{2}$ (squared correlation between direct genomic value and deregressed proofs) for Holstein validation bulls for milk yield traits when using different reference sets, 2 methods [genomic BLUP (GBLUP) vs. expectation maximization (EM)-Bayes R], and 2 SNP [high-density (HD) vs. 50K]

\begin{tabular}{|c|c|c|c|c|c|}
\hline \multirow[b]{2}{*}{ Ref set $^{1}$} & \multirow[b]{2}{*}{ Trait } & \multicolumn{2}{|c|}{ GBLUP } & \multicolumn{2}{|c|}{ EM-Bayes R } \\
\hline & & HD & $50 \mathrm{~K}$ & HD & $50 \mathrm{~K}$ \\
\hline \multirow[t]{4}{*}{ Set 7} & Milk yield & 0.65 & 0.65 & & \\
\hline & Fat yield & 0.49 & 0.51 & & \\
\hline & Protein yield & 0.49 & 0.49 & & \\
\hline & Average & 0.54 & 0.55 & & \\
\hline \multirow[t]{4}{*}{ Set 8} & Milk yield & 0.68 & 0.69 & & \\
\hline & Fat yield & 0.56 & 0.57 & & \\
\hline & Protein yield & 0.49 & 0.49 & & \\
\hline & Average & 0.58 & 0.58 & & \\
\hline \multirow[t]{4}{*}{ Set 9} & Milk yield & 0.65 & 0.64 & 0.67 & 0.66 \\
\hline & Fat yield & 0.49 & 0.51 & 0.53 & 0.53 \\
\hline & Protein yield & 0.48 & 0.48 & 0.49 & 0.48 \\
\hline & Average & 0.54 & 0.54 & 0.56 & 0.56 \\
\hline \multirow[t]{4}{*}{ Set 10} & Milk yield & 0.68 & 0.69 & 0.71 & 0.70 \\
\hline & Fat yield & 0.56 & 0.57 & 0.58 & 0.56 \\
\hline & Protein yield & 0.48 & 0.49 & 0.50 & 0.51 \\
\hline & Average & 0.58 & 0.58 & 0.60 & 0.59 \\
\hline
\end{tabular}

${ }^{1}$ EM-Bayes $\mathrm{R}$ was not run for reference (Ref) sets 7 and 8 because sets 9 and 10 were as good as sets 7 and 8 when predicting for Holstein bulls and EM-Bayes R was assumed to be better when the reference size was larger.

bulls first tested in NZ. When adding AU cows, the expectation of bias was less pronounced $(\sim 0.8)$ for bulls that were first tested elsewhere than bulls first tested in $\mathrm{NZ}(\sim 0.5)$.

For evaluating the reliability of GP for NZ validation bulls, we used DRP from AU genetic evaluation for both AU and NZ cows because we had access to the AU genetic evaluation rather than the NZ genetic evaluation. This approach may have contributed to the deviation of the regression coefficient of DRP on DGV from 1 . The extent of the possible bias caused by the merging $\mathrm{NZ}$ data to the $\mathrm{AU}$ genetic evaluation can be quantified in a subsequent analysis where we are planning to assess the benefit of adding NZ cow data on the reliability of GP in AU validation bulls as part of the objective of assessing the value of sharing cow data between the 2 countries.

\section{CONCLUSIONS}

In this study we explored the benefit of adding $\mathrm{AU}$ cows (Jer and Hol) into a RS that included different sets of NZ animals that ranged from purebred cows to all breed sets that included bulls and crossbred cows in a single as well as a multi-breed GP. The addition of AU cows to the NZ reference population (that included NZ cows, or cows and bulls) improved the reliability of GP for both Hol and Jer validation bulls for all traits. The reliability also increased in single breed reference populations when the NZ crossbred cows were added to reference populations that only included purebred NZ bulls and cows and AU cows. The full multi-breed RS, including crossbred cows (all NZ cows and bull as well as AU cow), provided reliabilities that were on a par with, but no higher than the single breed reference with crossbred NZ cows for Hol validation bulls. For Jer validation bulls the RS that included Jer cows and bulls and crossbred cows from NZ and Jer cows from AU was only marginally better than the all-breed, all-country RS. The advantage of a higher SNP chip density was small, although the HD SNP chip captures more of the genomic variance particularly for Hol than 50K SNP chip. The EM-Bayes R GP method was slightly (up to 3 percentage points) better than GBLUP. Overall, we observed that the reliability of GP for NZ bulls can be increased due to sharing cow populations with AU. The reliability of GP for the $3 \mathrm{MY}$ traits of NZ validation bulls can be increased by up to 4 (Hol) and 7 (Jer) percentage points by including about 50,583 Hol and 8,932 Jer cows from AU to a RS that included all NZ animals.

\section{ACKNOWLEDGMENTS}

We thank Gert Nieuwhof, Erica Jewell, and Paul Koh of DataGene (Melbourne, Australia) for their help with data reformatting. We thank Kon V. Konstantinov of DataGene (Melbourne, Australia) for running the genetic evaluation and providing the phenotypes used in this study to us. We thank DairyNZ (Hamilton, New 
Zealand) for providing the New Zealand data. This work is part of a project within the "DairyBio" programme and was funded by Agriculture Victoria Research (Melbourne, Australia), Dairy Australia (Melbourne, Australia), The Gardiner Foundation (Melbourne, Australia), and CRV (Arnhem, the Netherlands). The authors have not stated any conflicts of interest.

\section{REFERENCES}

Calus, M. P. L., Y. de Haas, and R. F. Veerkamp. 2013. Combining cow and bull reference populations to increase accuracy of genomic prediction and genome-wide association studies. J. Dairy Sci. 96:6703-6715. https://doi.org/10.3168/jds.2012-6013.

Cooper, T. A., G. R. Wiggans, and P. M. VanRaden. 2015. Short communication: Analysis of genomic predictor population for Holstein dairy cattle in the United States - Effects of sex and age. J. Dairy Sci. 98:2785-2788. https://doi.org/10.3168/jds.2014-8894.

Daetwyler, H. D., B. Villanueva, and J. A. Woolliams. 2008. Accuracy of predicting the genetic risk of disease using a genome-wide approach. PLoS One 3:e3395. https://doi.org/10.1371/journal.pone .0003395

Dassonneville, R., A. Baur, S. Fritz, D. Boichard, and V. Ducrocq. 2012. Inclusion of cow records in genomic evaluations and impact on bias due to preferential treatment. Genet. Sel. Evol. 44:40. https://doi.org/10.1186/1297-9686-44-40.

de Haas, Y., M. P. L. Calus, R. F. Veerkamp, E. Wall, M. P. Coffey, H. D. Daetwyler, B. J. Hayes, and J. E. Pryce. 2012. Improved accuracy of genomic prediction for dry matter intake of dairy cattle from combined European and Australian data sets. J. Dairy Sci. 95:6103-6112. https://doi.org/10.3168/jds.2011-5280.

de Roos, A. P. W., B. J. Hayes, and M. E. Goddard. 2009. Reliability of genomic breeding values across multiple populations. Genetics 183:1545-1553. https://doi.org/10.1534/genetics.109.104935.

de Roos, A. P. W., B. J. Hayes, R. J. Spelman, and M. E. Goddard. 2008. Linkage disequilibrium and persistence of phase on HolsteinFriesian, Jersey, and Angus cattle. Genetics 179:1503-1512. https: //doi.org/10.1534/genetics.107.084301.

Erbe, M., B. J. Hayes, L. K. Matukumalli, S. Goswami, P. J. Bowman, C. M. Reich, B. A. Mason, and M. E. Goddard. 2012. Improving accuracy of genomic predictions within and between dairy cattle breeds with imputed high-density single nucleotide polymorphism panels. J. Dairy Sci. 95:4114-4129. https://doi.org/10.3168/jds 2011-5019.

Gao, H., P. Madsen, U. S. Nielsen, G. P. Aamand, G. Su, K. Byskov, and J. Jensen. 2015. Including different groups of genotyped females for genomic prediction in a Nordic Jersey population. J. Dairy Sci. 98:9051-9059. https://doi.org/10.3168/jds.2015-9947.

Garrick, D. J., J. F. Taylor, and R. L. Fernando. 2009. Deregressing estimated breeding values and weighting information for genomic regression analyses. Genet. Sel. Evol. 41:55. https://doi.org/10 $.1186 / 1297-9686-41-55$.

Gilmour, A. R., B. J. Gogel, B. R. Cullis, and R. Thompson. 2009. ASReml User Guide Release 3.0 VSN International Ltd., Hemel Hempstead, UK.

Goddard, M. 2009. Genomic selection: Prediction of accuracy and maximization of long-term response. Genetica 136:245-257. https: //doi.org/10.1007/s10709-008-9308-0.

Habier, D., J. Tetens, F.-R. Seefried, P. Lichtner, and G. Thaller. 2010 The impact of genetic relationship information on genomic breeding values in German Holstein cattle. Genet. Sel. Evol. 42:5. https: //doi.org/10.1186/1297-9686-42-5.

Haile-Mariam, M., J. E. Pryce, C. Schrooten, and B. J. Hayes. 2015. Including overseas performance information in genomic evaluations of Australian dairy cattle. J. Dairy Sci. 98:3443-3459. https: //doi.org/10.3168/jds.2014-8785.
Hayes, B. J., P. J. Bowman, A. C. Chamberlain, K. Verbyla, and M. E. Goddard. 2009. Accuracy of genomic breeding values in multibreed dairy cattle populations. Genet. Sel. Evol. 41:51. https://doi .org/10.1186/1297-9686-41-51.

Hayes, B. J., G. Nieuwhof, and M. Haile-Mariam. 2017. A multi-trait approach to incorporating foreign phenotypes and genotypes in genomic predictions to increase accuracy and reduce bias. Proc. Assoc. Advmt. Anim. Breed. Genet. 22:265-268.

Howard, J. T., C. Maltecca, M. Haile-Mariam, B. J. Hayes, and J. E. Pryce. 2015. Characterizing homozygosity across United States, New Zealand and Australian Jersey cow and bull populations. BMC Genomics 16:187. https://doi.org/10.1186/s12864-015-1352 -4 .

Interbull. 2018. Appendix. Accessed Oct. 2018. http://www.interbull .org/static/mace_evaluations_archive/eval/prod-appen1-141.pdf.

Jenko, J., G. R. Wiggans, T. A. Cooper, S. A. E. Eaglen, W. G. L. Luff, M. Bichard, R. Pong-Wong, and J. A. Woolliams. 2017. Cow genotyping strategies for genomic selection in a small dairy cattle population. J. Dairy Sci. 100:439-452. https://doi.org/10.3168/jds .2016-11479.

Lee, S. H., and J. H. van der Werf. 2016. MTG2: An efficient algorithm for multivariate linear mixed model analysis based on genomic information. Bioinformatics 32:1420-1422. https://doi.org/10.1093/ bioinformatics/btw012.

Liu, Z. 2009. Deregressing MACE proofs for genomic evaluations. Proteje meeting, Brussels, Belgium.

Lund, M. S., A. P. de Roos, A. G. de Vries, T. Druet, V. Ducrocq, S. Fritz, F. Guillaume, B. Guldbrandtsen, Z. Liu, R. Reents, C. Schrooten, F. Seefried, and G. Su. 2011. A common reference population from four European Holstein populations increases reliability of genomic predictions. Genet. Sel. Evol. 43:43. https://doi.org/10 .1186/1297-9686-43-43.

Ma, P., M. S. Lund, G. P. Aamand, and G. Su. 2019. Use of a Bayesian model including QTL markers increases prediction reliability when test animals are distant from the reference population. J. Dairy Sci. 102:7237-7247. https://doi.org/10.3168/jds.2018-15815.

Porto-Neto, L. R., W. Barendse, J. M. Henshall, S. M. McWilliam, S. A. Lehnert, and A. Reverter. 2015. Genomic correlation: harnessing the benefit of combining two unrelated populations for genomic selection. Genet. Sel. Evol. 47:84. https://doi.org/10.1186/ s12711-015-0162-0.

Pryce, J. E., J. Arias, P. J. Bowman, S. R. Davis, K. A. Macdonald, G. C. Waghorn, W. J. Wales, Y. J. Williams, R. J. Spelman, and B. J. Hayes. 2012. Accuracy of genomic predictions of residual feed intake and 250-day body weight in growing heifers using 625,000 single nucleotide polymorphism markers. J. Dairy Sci. 95:21082119. https://doi.org/10.3168/jds.2011-4628.

Pryce, J. E., P. Douglas, C. M. Reich, A. J. Chamberlain, P. J. Bowman, T. T. T. Nguyen, B. A. Mason, C. P. Prowse-Wilkins, G. J Nieuwhof, T. Hancock, M. Shaffer, and B. J. Hayes. 2017. Reliabilities of Australian dairy genomic breeding values increase through the addition of genotyped females with excellent phenotypes. Proc. Assoc. Advmt. Anim. Breed. Genet. 22:133-136.

Pryce, J. E., B. Gredler, S. Bolormaa, P. J. Bowman, C. Egger-Danner, C. Fuerst, R. Emmerling, J. Sölkner, M. E. Goddard, and B. J. Hayes. 2011. Short communication: Genomic selection using a multi-breed, across-country reference population. J. Dairy Sci. 94:2625-2630. https://doi.org/10.3168/jds.2010-3719.

Schöpke, K., and H. Swalve. 2016. Review: Opportunities and challenges for small populations of dairy cattle in the era of genomics. Animal 10:1050-1060. https://doi.org/10.1017/S1751731116000410.

$\mathrm{Su}$, G., B. Guldbrandtsen, V. R. Gregersen, and M. S. Lund. 2010. Preliminary investigation on reliability of genomic estimated breeding values in the Danish Holstein population. J. Dairy Sci. 93:1175-1183. https://doi.org/10.3168/jds.2009-2192.

Su, G., P. Ma, U. Nielsen, G. Aamand, G. Wiggans, B. Guldbrandtsen, and M. Lund. 2016. Sharing reference data and including cows in the reference population improve genomic predictions in Danish Jersey. Animal 10:1067-1075. https://doi.org/10.1017/ S1751731115001792. 
van den Berg, I., D. Boichard, and M. S. Lund. 2016. Sequence variants selected from a multi-breed GWAS can improve the reliability of genomic predictions in dairy cattle. Genet. Sel. Evol. 48:83. https://doi.org/10.1186/s12711-016-0259-0.

VanRaden, P. M., K. M. Olson, D. J. Null, M. Sargolzaei, M. Winters, and J. B. C. H. M. van Kaam. 2012. Reliability increases from combining 50,000- and 777,000-marker genotypes from four countries. Interbull Bull. 46:75-79.

VanRaden, P. M., C. P. Van Tassell, G. R. Wiggans, T. S. Sonstegard, R. D. Schnabel, J. F. Taylor, and F. S. Schenkel. 2009. Reliability of genomic predictions for north American Holstein bulls. J. Dairy Sci. 92:16-24. https://doi.org/10.3168/jds.2008-1514.

Wang, T., Y. P. Chen, P. J. Bowman, M. E. Goddard, and B. J. Hayes. 2016. A hybrid expectation maximisation and MCMC sampling algorithm to implement Bayesian mixture model based genomic prediction and QTL mapping. BMC Genomics 17:744. https://doi .org/10.1186/s12864-016-3082-7.

Wientjes, Y. C. J., P. Bijma, J. Vandenplas, and M. P. L. Calus. 2017. Multi-population genomic relationships for estimating current ge- netic variances within and genetic correlations between populations. Genetics 207:503-515. https://doi.org/10.1534/genetics.117 .300152 .

Wientjes, Y. C. J., M. P. L. Calus, P. Duenk, and P. Bijma. 2018. Required properties for markers used to calculate unbiased estimates of the genetic correlation between populations. Genet. Sel. Evol. 50:65. https://doi.org/10.1186/s12711-018-0434-6.

Wiggans, G. R., T. A. Cooper, P. M. VanRaden, and J. B. Cole. 2011 Technical note: Adjustment of traditional cow evaluations to improve accuracy of genomic predictions. J. Dairy Sci. 94:6188-6193. https://doi.org/10.3168/jds.2011-4481.

Winkelman, A. M., D. L. Johnson, and B. L. Harris. 2015. Application of genomic evaluation to dairy cattle in New Zealand. J. Dairy Sci. 98:659-675. https://doi.org/10.3168/jds.2014-8560.

Yang, J., B. Benyamin, B. McEvoy, S. Gordon, A. Henders, D. Nyholt, P. Madden, A. Heath, N. Martin, G. Montgomery, M. E. Goddard, and P. M. Visscher. 2010. Common SNPs explain a large proportion of the heritability for human height. Nat. Genet. 42:565-569. https://doi.org/10.1038/ng.608. 